\title{
Observations of Ag Diffusion in Ion Implanted SiC
}

Tyler J. Gerczak ${ }^{1, *}$, Bin Leng ${ }^{2}$, Kumar Sridharan ${ }^{2}$, Jerry L. Hunter Jr. ${ }^{3}$, Andrew J. Giordani ${ }^{3}$, Todd R. Allen ${ }^{2}$

${ }^{1}$ Materials Science Program, University of Wisconsin, Madison, WI 53706, USA

${ }^{2}$ Engineering Physics Dept., University of Wisconsin, Madison, WI 53706, USA

${ }^{3}$ Nanoscale Characterization and Fabrication Laboratory, Virginia Tech, Blacksburg, VA 2060 USA

*Currently at Oak Ridge National Laboratory, Oak Ridge, TN 37831, USA

\section{Corresponding author:}

Tyler J. Gerczak

P.O. Box 2008

Oak Ridge, TN 37831 (USA)

Phone: +1 8655748766

Email: gerczaktj@ornl.gov 


\title{
Observations of Ag Diffusion in Ion Implanted SiC
}

Tyler J. Gerczak ${ }^{1, *}$, Bin Leng ${ }^{2}$, Kumar Sridharan ${ }^{2}$, Jerry L. Hunter Jr. ${ }^{3}$, Andrew J. Giordani ${ }^{3}$, Todd R. Allen ${ }^{2}$

${ }^{1}$ Materials Science Program, University of Wisconsin, Madison, WI 53706, USA

${ }^{2}$ Engineering Physics Dept., University of Wisconsin, Madison, WI 53706, USA

${ }^{3}$ Nanoscale Characterization and Fabrication Laboratory, Virginia Tech, Blacksburg, VA 2060 USA

*Currently at Oak Ridge National Laboratory, Oak Ridge, TN 37831, USA

\begin{abstract}
:
The nature and magnitude of $\mathrm{Ag}$ diffusion in $\mathrm{SiC}$ has been a topic of interest in connection with the performance of tristructural isotropic (TRISO) coated particle fuel for high temperature nuclear reactors. Ion implantation diffusion couples have been revisited to continue developing a more complete understanding of Ag fission product diffusion in SiC. Ion implantation diffusion couples fabricated from single crystal $4 \mathrm{H}-\mathrm{SiC}$ and polycrystalline $3 \mathrm{C}-\mathrm{SiC}$ substrates and exposed to $1500-1625^{\circ} \mathrm{C}$, were investigated by transmission electron microscopy and secondary ion mass spectrometry (SIMS). The high dynamic range of SIMS allowed for multiple diffusion régimes to be investigated, including enhanced diffusion by implantation-induced defects and grain boundary (GB) diffusion in undamaged SiC. Estimated diffusion coefficients suggest GB diffusion in bulk SiC does not accurately reflect the release observed from TRISO fuel.
\end{abstract}

Keywords: Silicon carbide, TRISO, ion implantation, silver, diffusion 


\section{Introduction}

The development of advanced nuclear reactor concepts has prompted a need for materials with high performance under extreme environments. Silicon carbide ( $\mathrm{SiC}$ ) possesses high temperature strength, chemical inertness, and a low neutron cross-section making it an ideal material for advanced reactor core components [1]. SiC has found a prominent role in the design of tristructural isotropic (TRISO) coated particle fuel. The TRISO fuel construction, as identified by the US DOE Advanced Gas Reactor Fuel Development Program, consists of a mixed uranium-dioxide and uranium-carbide fuel kernel surrounded by a approximately $100 \mu \mathrm{m}$ carbonaceous buffer layer and successive isotropic layers of approximately $35 \mu \mathrm{m}$ inner pyrolytic carbon (IPyC), approximately $40 \mu \mathrm{m}$ chemical-vapor-deposited (CVD) SiC, and approximately $35 \mu$ m outer pyrolytic carbon (OPyC) [2]. In the TRISO fuel design the CVD-SiC layer acts as a structural component and as a barrier to fission products and radioisotopes not stabilized in the fuel kernel.

While modern TRISO fuel has demonstrated excellent retention of fission products and radioisotopes, variable release of ${ }^{110 \mathrm{~m}} \mathrm{Ag}$ from intact particles has continued to be observed [3]. This release of $\mathrm{Ag}$ from intact TRISO particles represents a legacy problem, which has been a focus of research since the 1970's [4,5]. Comprehensive reviews of the reported literature related to Ag release from TRISO fuel and Ag diffusion in $\mathrm{SiC}$ are presented by van Rooyen et al. [6] and Malherbe [7]. No consensus has been reached concerning the mechanism responsible for Ag release from TRISO fuel, however, it is suggested that the release is influenced by the $\mathrm{SiC}$ layer microstructure as particles with large columnar-grained $\mathrm{SiC}$ layers have been observed to release a larger fraction of $\mathrm{Ag}$ fission product inventory relative to particles with fine-grained SiC layers [8]. The two primary competing hypotheses for the observed release are grain boundary dependent transport [4,9-15] and micro-crack vapor transport $[16,17]$. The understanding of the Ag release mechanism from TRISO fuel is derived from Ag release measurements from irradiated TRISO fuel [4,5,18-24], surrogate Ag diffusion studies [9-14,16,17,25], and computation simulation studies $[15,17,26,27]$. The measured diffusion coefficients for release from 
TRISO fuel are observed to be orders of magnitude greater than the surrogate diffusion and simulations studies. The reason for the observed discrepancy is not explicitly known.

A primary variable between the TRISO release and surrogate diffusion studies is the influence of irradiation damage on observed Ag transport. Molecular dynamics simulations by Méric de Bellefon et al. [27] have postulated that irradiation induced microstructural defects and variations in grain boundary (GB) network of the SiC layer may significantly influence the observed Ag transport in SiC. Similarly, in surrogate ion implantation studies, implantation effects have also been observed to influence the redistribution of $\mathrm{Ag}$ in $\mathrm{SiC}$ implanted at room temperature to $600^{\circ} \mathrm{C}[9,10,13,28]$. The reported surrogate diffusion studies focus on investigation of $\mathrm{Ag}$ diffusion in unirradiated $\mathrm{SiC}$ or in the case of ion implantation diffusion studies, SiC substrates with an irradiated implantation layer adjacent to unirradiated $\mathrm{SiC}$. This variation in $\mathrm{SiC}$ substrates and experimental methodology may contribute to the reported discrepancies in $\mathrm{Ag}$ diffusion coefficients $\left(D^{A g}\right)$ obtained from surrogate studies and those from TRISO release analysis.

Additionally, the physical properties of $\mathrm{SiC}$ which make it an ideal fission product barrier material for nuclear fuel applications also present challenges for investigating impurity diffusion behavior for high atomic number elements in $\mathrm{SiC}$, notably due to low impurity solubility limits $(S), S(T)<1 \times 10^{17}$ $\mathrm{at} / \mathrm{cm}^{3}$ at $2150^{\circ} \mathrm{C}$ [29], and large migration energy barriers [30]. For diffusion studies, these challenges require high temperature exposures to drive diffusion to measurable diffusion depths and concentrations by available analysis techniques.

For the temperatures of interest to TRISO operations and accident conditions, $800-1600^{\circ} \mathrm{C}$ [31], elemental Ag is primarily in the liquid phase with a high vapor pressure. This is an issue for traditional diffusion couple designs as it leads to possible $\mathrm{Ag}$ dissolution in $A g_{(l)}$ [32] and difficulty in maintaining a consistent diffusion surface. Ion implantation diffusion couples provide a consistent, buried Ag source for investigating diffusion in $\mathrm{SiC}$ at elevated temperatures where diffusion in the implanted substrate is indicated by an extension of the implanted species past the implantation peak after thermal exposure and has been observed for $\mathrm{B}$ and $\mathrm{Al}$ in $\mathrm{SiC}[33,34]$. In this study, ion implantation diffusion couples are 
investigated by secondary ion mass spectrometry (SIMS) depth profiling; SIMS provides an expanded dynamic range of $\mathrm{Ag}$ detection relative to previously reported $\mathrm{Ag}$ ion implantation studies

$[9,10,13,16,17]$. The expanded dynamic range allows for the investigation of Ag diffusion phenomena at Ag concentrations of approximately $1 \times 10^{20} \mathrm{at} / \mathrm{cm}^{3}$ to $1 \times 10^{15} \mathrm{at} / \mathrm{cm}^{3}$, yielding additional insight to further understand Ag release from TRISO fuel.

\section{Materials and Methods}

\subsection{Implantation and Thermal Exposure}

Polycrystalline CVD 3C-SiC from Rohm and Haas (standard grade SC-001) and single crystal 4H-SiC wafers $4^{\circ}$ off (1000) from Cree, Inc. were used as ion implantation substrates for diffusion studies. Polycrystalline 3C-SiC samples were prepared from bulk samples and were polished to an arithmetic surface roughness $\left(\mathrm{R}_{\mathrm{a}}\right)<10 \mathrm{~nm}$ using successively finer diamond polishing media and a final polish of $0.05 \mu \mathrm{m}$ colloidal silica. The single crystal $4 \mathrm{H}-\mathrm{SiC}$ wafers were obtained from Cree, Inc. with a $\mathrm{R}_{\mathrm{a}}<10 \mathrm{~nm}$. Roughness values were measured using a Zygo optical profilometer. The polycrystalline 3C$\mathrm{SiC}$ substrates were implanted with two separate dose conditions, $400 \mathrm{kV} \mathrm{Ag}{ }^{+}$to $1 \times 10^{14} \mathrm{ion} / \mathrm{cm}^{2}$ and $5 \times 10^{14}$ ions $/ \mathrm{cm}^{2}$, at $300^{\circ} \mathrm{C}$ at the Michigan Ion Beam Laboratory (MIBL) through the Advanced Test Reactor National User Facility (ATR-NSUF) program. The single crystal 4H-SiC substrates were implanted to a dose of $5 \times 10^{14}$ ions $/ \mathrm{cm}^{2}$ at identical conditions to the polycrystalline $3 \mathrm{C}$-SiC substrates. The implantation dose and the $300^{\circ} \mathrm{C}$ implantation temperature were selected to avoid amorphization of the SiC substrate during implantation. Following Ag implantation a 200-250 nm diamond-like-carbon (DLC) coating was deposited on the SiC implantation surface to protect the sample during thermal exposure.

Individual samples, approximately $8 \mathrm{~mm}$ x $8 \mathrm{~mm}$, were cut from the bulk implanted substrates for thermal exposure. Individual samples for thermal exposure were mated with an as-polished 3C-SiC sample using graphite paste to further protect the implantation surface. The samples were sealed in a thick-walled quartz ampoule with excess coarse SiC powder to limit surface decomposition [35]. 
Approximately, $0.05 \mathrm{~g}$ of $\mathrm{Ag}$ foil were encapsulated in the isolated sample chamber along with the diffusion sample to limit $\mathrm{Ag}$ out-diffusion from the $\mathrm{Ag}$ implanted $\mathrm{SiC}$ substrates. Samples were exposed to $1500-1569^{\circ} \mathrm{C}$ in an MTI GSL $1600 \mathrm{X}-80$ tube furnace and at $1625^{\circ} \mathrm{C}$ in a Lindberg Blue tube furnace. The self-contained samples were inserted and removed at temperature followed by a quenched step to limit diffusion contributions during transient heating and cooling. Temperatures were monitored with an external Type-B thermocouple placed in the center of the tube furnace hot zone. After thermal exposure, the ion implantation substrates were investigated by transmission electron microscopy (TEM), scanning transmission electron microscopy (STEM), and SIMS to understand the change in Ag distribution. Table 1 shows the ion implantation diffusion couples investigated in this study.

Table 1: Ion implantation diffusion couple exposure conditions for implantation doses of $5 \times 10^{14}$ ions $/ \mathrm{cm}^{2}$, *indicates $1 \times 10^{14}$ ions $/ \mathrm{cm}^{2}$ also included

\begin{tabular}{|l|l|l|l|l|}
\hline Temperature $\left({ }^{\circ} \mathrm{C}\right)$ & $1500^{\circ} \mathrm{C}$ & $1535^{\circ} \mathrm{C}$ & $1569^{\circ} \mathrm{C}$ & $1025^{\circ} \mathrm{C}$ \\
\hline Time (hours) & $5,10,20$ hours $^{*}$ & 10 hours $^{*}$ & $5,10,20$ hours & 1 hour \\
\hline
\end{tabular}

\subsection{S/TEM Analysis}

S/TEM samples for investigation were prepared by traditional focused ion beam (FIB) lift-out techniques using a Zeiss CrossBeam Dual Beam FIB/SEM at the at the University of Wisconsin-Madison Materials Science Center (UWMSC). The FIB lift-out technique provided cross-sectional TEM samples of the SiC structure along the implantation and diffusion direction. Bright Field (BF) TEM analysis was performed using a Technai TF-30 at $300 \mathrm{kV}$. Selected area diffraction (SAD) patterns of the implantation layer and unaffected $\mathrm{SiC}$ beyond the implantation layer were obtained using a $300 \mathrm{~nm}$ aperture. Annular Dark Field (ADF) micrographs were obtained using a FEI Titan aberration-corrected STEM at the UWMSC to provide additional mass-contrast to aid in resolving the nature of the Ag after implantation and thermal exposure.

\section{$\underline{2.3 \text { SIMS Analysis }}$}


SIMS analysis was conducted using a Cameca IMS 7f-GEO magnetic sector SIMS. Depth profiles were obtained for $\mathrm{Ag}$ in $\mathrm{SiC}$ by rastering a $5 \mathrm{keV} \mathrm{O}_{2}^{+}$ion beam over a 200 x $200 \mu \mathrm{m}$ area with a $33 \mu \mathrm{m}$ diameter optically gated analysis area. The SIMS analysis was performed at the Institute of Critical Technology and Applied Science Nanoscale Characterization and Fabrication Laboratory at Virginia Tech. ${ }^{107} \mathrm{Ag}$ intensity was measured as a function of time and the measured intensity was correlated to $\mathrm{Ag}$ concentration $([\mathrm{Ag}])$ using a relative sensitivity factor of $1.10-1.32 \times 10^{23} \mathrm{at} / \mathrm{cm}^{3}$ calculated from of the asimplanted (AI) $\mathrm{SiC}$ substrates using the isotope ${ }^{28} \mathrm{Si}$ as the bulk $\mathrm{SiC}$ reference intensity. Relative sensitivity factors were determined for all AI substrates (polycrystalline $3 \mathrm{C}-\mathrm{SiC} 1 \times 10^{14} \mathrm{ions} / \mathrm{cm}^{2}$ and $5 \times 10^{14}$ ions $/ \mathrm{cm}^{2}$, and single crystal $4 \mathrm{H}-\mathrm{SiC} 5 \times 10^{14} \mathrm{ions} / \mathrm{cm}^{2}$ ) where the range in relative sensitivity factors is representative of minor experimental variations for each AI substrate. Crater depths were determined by measuring the SIMS sputter crater using a Zygo optical profilometer to correlate sputtering time with depth.

\section{Results and Discussion}

\subsection{S/TEM Analysis}

Figure 1 shows a BF-TEM comparison of the implantation zone for the polycrystalline 3C-SiC $5 \times 10^{14}$ ions $/ \mathrm{cm}^{2} \mathrm{AI}$ and $1569^{\circ} \mathrm{C} 20$ hour exposure samples. SAD patterns, inset in Figure 1, indicate the implantation zone remained crystalline and suggests the implanted Ag remained in solution after implantation as no segregated features are observed in the implantation zone, which is identified as a darker band parallel to the implantation surface. Post thermal exposure, a fine structure is observed in the primary implantation region, indicating implanted $\mathrm{Ag}$ redistributes after thermal annealing in the crystalline substrate. Figure 2 shows the BF-TEM micrographs of the single crystal $4 \mathrm{H}-\mathrm{SiC} 5 \times 10^{14}$ ions $/ \mathrm{cm}^{2} \mathrm{AI}$ and $1569^{\circ} \mathrm{C} 20$ hours exposure samples. Similar to the polycrystalline $3 \mathrm{C}$-SiC substrates, no evidence of amorphization is apparent as the SAD pattern indicates a crystalline substrate remains after implantation. Following thermal exposure fine-scale segregated Ag features are also observed in the single crystal $4 \mathrm{H}-\mathrm{SiC}$ samples. No insight on the structure of the fine-scale segregated $\mathrm{Ag}$ features was determined from the SAD analysis of the thermally exposed samples. 
ADF provides diffraction contrast and mass contrast for imaging Ag impurities in the low atomic mass $\mathrm{SiC}$ matrix. Figure 3 shows a comparison of the polycrystalline $3 \mathrm{C}-\mathrm{SiC} 5 \times 10^{14} \mathrm{ions} / \mathrm{cm}^{2} \mathrm{AI}$ and $1500^{\circ} \mathrm{C} 10$ hours thermal exposure, confirming fine-scale, high atomic mass $\mathrm{Ag}$ features form after thermal exposure in the region associated with the implantation zone. The affected depth is measured to be approximately 300-350 nm with no obvious features observed at greater depths.

\subsection{Ion Implantation Diffusion Analysis}

\subsubsection{SIMS Results from Single Crystal 4H-SiC Diffusion Couples}

Figure 4 shows an isochronal comparison of Ag depth profiles for single crystal $4 \mathrm{H}-\mathrm{SiC}$ substrates exposed to temperatures $1500-1569^{\circ} \mathrm{C}$ for 10 hours. The Ag profile in the AI single crystal $4 \mathrm{H}-$ $\mathrm{SiC}$ substrate presents a singular Ag concentration peak at approximately $140 \mathrm{~nm}$ with a skewed $\mathrm{Ag}$ concentration past the primary peak into the bulk substrate from expected ion straggling. The thermally exposed single crystal $4 \mathrm{H}-\mathrm{SiC}$ substrates indicate a bi-modal Ag distribution for all thermally exposed samples, with the primary peak remaining at approximately $140 \mathrm{~nm}$ and a secondary peak at approximately $500 \mathrm{~nm}$. Figure 5 shows Ag depth profiles for the isothermal exposures of $1569^{\circ} \mathrm{C} 5-20$ hours. The isothermal comparison presents a similar observation in that no significant variation in the $\mathrm{Ag}$ concentration profile past the primary implantation peak is observed as a function of time, this implies the observed redistribution of the implanted Ag concentration past the primary implantation peak is independent of the exposure time and temperature for the conditions investigated.

The correlation of the Ag depth profile with the SRIM damage profile is shown in Figure 6. A scaling factor of 1.28 was used to account for the underestimation of the heavy ion interaction with $\mathrm{SiC}$ in SRIM [36]. The observed Ag concentration minimum and secondary peak, as seen in Figures 4 and 5, coincides with the reduction in implantation induced damage estimated in SRIM and is beyond the depth containing end-of-range defects identified by BF-TEM. The consistent Ag depth profiles suggest the redistribution of $\mathrm{Ag}$ past the primary implantation peak is due to the annealing-out of a finite population of implantation induced defects in the single crystal $4 \mathrm{H}-\mathrm{SiC}$ substrate.

\subsubsection{Nature of Defects Contributing to Diffusion}

Page 8 of 34 
The diffusion coefficient, $D$, for equilibrium impurity diffusion is described by an Arrhenius relationship, shown in Equation 1. In Equation 1, $D_{o}\left(\mathrm{~m}^{2} / \mathrm{s}\right)$ is a pre-exponential term which describes the physical nature of the diffusion mechanism, $k$ is Boltzmann's constant $(e V / K), T$ is temperature $(K)$ and $Q$ is the activation energy $(e V)$. The activation energy, $Q$, is composed of a migration energy barrier, $E_{m}$, and a formation energy barrier, $E_{f}$. Here $E_{m}$, in general terms, describes the energy barrier for a specific mechanism to proceed forward, while $E_{f}$ describes the probability that a specific defect is present to participate in the diffusion process. The activation energy, $Q$, is approximated as the sum of both $E_{m}$ and $E_{f}$

Equation 1: $D=D_{o} \exp \left(\frac{-Q}{k T}\right)$

In simple cases, enhanced diffusion can occur from irradiation effects when non-equilibrium point defect concentrations contributing to the diffusion mechanism are present after implantation. Under enhanced diffusion conditions resulting from non-equilibrium point defects the activation energy for diffusion is not dependent on $E_{f}$ and is dominated by $E_{m}$ and trapping effects [37]. When trapping effects are limited, the enhanced diffusion coefficient, $D^{\text {enh }}$, is increased proportional to the concentration of nonequilibrium point defects remaining after implantation where the barrier to diffusion becomes dominated by $E_{m}$ for the specific mechanism. Equation 2 demonstrates this principle for a direct interstitialcy diffusion mechanism [38]. In Equation 2, $D^{\text {enh. }}$, is the enhanced diffusion coefficient, $\left[A_{I}\right]$, is the impurity interstitial concentration, $\left[A_{I}^{e q .}\right]$ is the equilibrium impurity interstitial concentration and $D_{A}^{e q .}$ is the equilibrium diffusion coefficient. [ $A_{I}^{e q .}$ ] is dependent on the $E_{f}$, as described by Equation 3 [14], leading to the enhanced diffusion coefficients dependence on $E_{m}$.

Equation 2: $D_{A}^{e n h .}=D_{A}^{e q \cdot} \frac{\left[A_{I}\right]}{\left[A_{I}^{\text {eq. }}\right]}$

Equation $3:\left[A_{I}^{\text {eq. }}\right] \approx$ \# defect sites $/$ unit volume $\times \exp \left(\frac{-E_{f}}{k T}\right)$

Residual point defects generated during implantation are expected to be present in the $\mathrm{SiC}$ substrate after the implantation process at $300^{\circ} \mathrm{C}$ and available to contribute to enhanced diffusion. Self- 
interstitials and vacancies have different annealing temperatures in SiC. The annealing temperatures of vacancies in the $\mathrm{Si}$ and $\mathrm{C}$ sublattices are expected to be $800^{\circ} \mathrm{C}$ and $450-500^{\circ} \mathrm{C}$, respectively [39]. The corresponding migration barriers, $E_{m}$, for vacancy motion are 5.2-6.5 eV for Si sublattice vacancies, $V_{S i}$, and 3.5-5.2 eV for $\mathrm{C}$ sublattice vacancies, $V_{C}$ [39]. The effective diffusion length for intrinsic vacancy diffusion is estimated from $x=\sqrt{D t}$, where $x$ is an approximation of the diffusion length scale. For the implantation conditions, approximately $40 \mathrm{~min}$ implantation at $300^{\circ} \mathrm{C}$, the estimated effective vacancy diffusion lengths are $4.3 \times 10^{-26} \mathrm{~nm}$ and $1.5 \times 10^{-29} \mathrm{~nm}$ using reported diffusion coefficients of $V_{C}$ and $V_{S i}$ respectively $[40,41]$. This highlights the limited vacancy mobility at $300^{\circ} \mathrm{C}$. The picture of remaining interstitials generated by implantation damage is less clear. The insight on the nature of self-interstitials in $\mathrm{SiC}$ as determined by $a b$ initio simulations suggest several interstitial configurations are possible: tetragonal coordinated, split dumbbell [100] and split dumbbell [110] [26,42]. The mobility of these selfinterstitial defects is expected to be greater than vacancies in $\mathrm{SiC}$, however, the complex nature of the stable SiC interstitials suggest multiple possible interstitial diffusion pathways [39]. The expected prevalent migration pathway for $\mathrm{C}$ interstitials is a direct interstitial hop between two adjacent split [100] interstitials, with a $E_{m}$ between $0.91-1.68 \mathrm{eV}$ [39]. Si self-interstitials are suggested to diffuse via a kickout mechanism in SiC for split and tetragonally coordinated interstitials. The barrier for Si self-interstitial diffusion is expected to range from 3.4-3.56 eV [39,43]. A comparison of the magnitude of the $E_{m}$ for vacancies and interstitials suggest $\mathrm{Si}$ self-interstitials may remain after implantation as the $E_{m}$ is equivalent to the low end of the $\mathrm{C}$ vacancy $E_{m}$ which corresponds to a defect annealing temperature of $450-500^{\circ} \mathrm{C}$. The $E_{m}$ of $\mathrm{C}$ self-interstitials is approximately $2 \mathrm{eV}$ lower, implying that the defects are likely mobile at $300^{\circ} \mathrm{C}$ and may anneal out. The energetics of residual defects formed by the implantation process suggests excess point defects, notably Si and C vacancies and Si self-interstitials, are available to participate in the Ag diffusion process after the implantation is halted.

No direct measurement of the nature of the impurity Ag after implantation has been made in this study. A previous ion implantation study by Xiao et al. [17] reported that implanted Ag exists 
interstitially after implantation at $377^{\circ} \mathrm{C}$ as determined by Rutherford Backscatter Spectroscopy channeling experiments. Alternately, ab initio simulations by Schrader et al. [26] suggest the most stable Ag defect in the lattice is the $A g_{S i} V_{C}^{-1}$ complex, implying Ag prefers to sit in a complex-substitutional site after implantation. From the same study the calculated $E_{m}$ for tetragonal $\mathrm{Ag}$ interstitials is approximately $0.89 \mathrm{eV}$. The energetics for intrinsic diffusion of $\mathrm{Ag}$ interstitials from ab initio simulations, are $D_{o}$ approximately $9.57 \times 10^{-8} \mathrm{~m}^{2} / \mathrm{s}$ and $Q_{\text {int }}$ approximately $0.89 \mathrm{eV}$ [26]. A diffusion length scale, $x$, for $\mathrm{Ag}$ interstitial diffusion during the $300^{\circ} \mathrm{C}$ implantation process is estimated to be approximately $1-2 \mu \mathrm{m}$ based on the energetics of intrinsic interstitial diffusion. The magnitude of the activation energy and estimated diffusion length scale for Ag interstitial diffusion would suggest some Ag interstitials are mobile and may anneal out during the implantation process.

The nature of the implantation induced point defects for the Ag-SiC system is not explicitly known, and as such direct confirmation of the mechanism responsible for the Ag diffusion in single crystal $4 \mathrm{H}-\mathrm{SiC}$ is not possible. TEM analysis indicates trapping of implanted $\mathrm{Ag}$ at end-of-range largescale defects, as shown in Figures 1 and 2, which are formed due to a super-saturation of point defect in the primary implantation peak. The distribution of implantation induced vacancy and self-interstitial point defects are expected to vary as a function of depth in the implanted substrate with excess vacancies present at the near surface régime to the projected end-of-range and excess interstitials beginning to dominate beyond the projected end-of-range $[44,45]$. In Si substrate implantations this difference in point defect populations is expected to influence enhanced impurity diffusion [46]. The observed $\mathrm{Ag}$ diffusion associated with the $\mathrm{Ag}$ concentration minima in the single crystal $4 \mathrm{H}-\mathrm{SiC}$ depth profiles occur in the excess interstitial régime. This suggests excess vacancies provide sufficient trapping sites to immobilize implanted Ag from the implantation surface to the end-of-range while the redistribution of Ag past the transition from excess vacancies to excess interstitials implies the observed Ag diffusion is dependent on mobile interstitials. The secondary segregation peak occurs beyond the primary implantation peak and is expected to be resultant from Ag gettering at implantation induced impurity sinks in the irradiated 
substrate. This implantation induced gettering trans-end-of-range has been observed in Si ion implantations and is attributed to trapping of mobile interstitials at small interstitial features [47-49]. The suggested dependence of the observed enhanced Ag diffusion on the vacancy and interstitial populations provides evidence for two potential mechanisms: direct interstitial diffusion and a kick-out diffusion mechanism.

\subsubsection{Discussion of Mechanisms Contributing to Enhanced Diffusion}

A direct interstitial diffusion mechanism describes the scenario where implanted $\mathrm{Ag}$ resides interstitially after implantation, as suggested by Xiao et al. [17]. Here the excess implanted Ag interstitial concentration would be expected to be mobile at the exposure temperatures $\left(+1500^{\circ} \mathrm{C}\right)$ until reaching an interstitial sink, due to the expected low $E_{m}$, describing the observed rapid diffusion. This would account for the observed bi-modal distribution as an increased sink density is present at the near-surface due to excess vacancies, at the end-of-range implantation peak due to large scale defects, and in the region past the primary peak (trans-end-of-range defects).

In the simplified kick-out process an excess self-interstitial (I) replace an Ag substitutional atom $\left(A g_{S}\right)$ yielding a $\mathrm{Ag}$ interstitial atom $\left(A g_{I}\right)$, shown in Equation 4. The Ag interstitial is then available to diffuse by a direct interstitial mechanism or by the reverse reaction. However, this simplified process is likely more complicated in $\mathrm{SiC}$ due to the multiple sublattices and the presence of anti-site defects.

Equation 4: $A g_{s}+I \Leftrightarrow A g_{I}$

From Equation 4 impurity diffusivity is dictated by the Ag impurity concentrations, which are coupled to the self-interstitial concentration. For systems where the kick-out mechanism is active, under equilibrium conditions the concentration of substitutional impurities can be significantly greater than that of the interstitial impurities, however, the vacancy diffusivity can be much lower than the interstitial diffusivity [50]. This holds for the energetics of $\mathrm{Ag}$ defects in $\mathrm{SiC}$ where $E_{f}$ is lower for substitutional defects compared to interstitials and $E_{m}$ of interstitials is expected to be lower than $E_{m}$ of substitutional defects 
[26]. Thus after implantation, the kick-out mechanism effectively mobilizes a non-equilibrium fraction of the implanted impurity atoms leading to enhanced diffusion.

For the kick-out mechanism, $\left[\mathrm{Ag}_{I}\right]$ cannot be estimated directly as insight on the reaction constant for Equation 4 must be known in addition to trapping effects. The +1 model assumes a self-interstitial, $I$, is formed for every incident ion [51]. Assuming Equation 4 proceeds completely with limited trapping effects, an upper bounds estimate of $\left[\mathrm{Ag}_{I}\right]$ approximately $1 \times 10^{-4}$ to $1 \times 10^{-8}$ can be made from the +1 model, and this is also proportional to the $\left[\mathrm{Ag}_{I}\right]$ for a direct intersticiallcy approximation of all $\mathrm{Ag}$ resting interstitially after implantation. The estimated value for $\left[\mathrm{Ag}^{\text {eq. }}{ }_{\mathrm{I}}\right]$ is approximately $1 \times 10^{-30}$ at $1500^{\circ} \mathrm{C}$ based on the $E_{f}$ approximately $10.49 \mathrm{eV}$ from ab initio calculations [26]. This equates to a $\left[A g_{I}\right] /\left[\mathrm{Ag}^{e q .}{ }_{I}\right] \approx$ $1 \times 10^{22-26}$, leading to a proportional increase in $D^{\text {enh. }}$ and represents an upper bounds in the magnitude of $D^{e n h .}$ as the role of trapping is not considered. The consistent single crystal $4 \mathrm{H}-\mathrm{SiC}$ depth profiles indicate the mobile point defects are annealed out after $1500^{\circ} \mathrm{C}$ at 10 hours and $1625^{\circ} \mathrm{C}$ at 1 hour. A lower bounds on $D^{e n h}$ are estimated from the observed diffusion length scale, $\mathrm{x}$, from the Ag concentration minima to the trans-end-of-range peak of approximately $100 \mathrm{~nm}$. The estimated lower bounds of $D^{\text {enh. }}$ for the shortest exposure time, the $1625^{\circ} \mathrm{C}$ at 1 hour exposure, is approximately $1 \times 10^{-18} \mathrm{~m}^{2} / \mathrm{s}$. This value is reasonable in comparison to the calculated $D^{A g}$ for interstitial lattice diffusion from ab initio simulation of approximately $2.5 \times 10^{-30} \mathrm{~m}^{2} / \mathrm{s}$ at $1625^{\circ} \mathrm{C}$ as it represents an approximately $1 \times 10^{11}$ increase in $D^{A g}$ which is below the estimated upper bound for $D^{e n h}$.

Ultimately, the extent of the enhanced diffusion and responsible mechanism observed in single crystal $4 \mathrm{H}-\mathrm{SiC}$ exposures is unknown due to a limited understanding of the residual point defects after implantation and magnitude of the specific defect concentrations. However, the correlation of the damage profile with bi-modal Ag redistribution indicates the non-equilibrium interstitial point defects, which remain after ion implantation, contribute to the observed diffusion of $\mathrm{Ag}$ in single crystal $4 \mathrm{H}-\mathrm{SiC}$. The consistent $\mathrm{Ag}$ concentration profiles past the primary peak at $1569^{\circ} \mathrm{C} 5,10,20$ hours exposures for single 
crystal $4 \mathrm{H}-\mathrm{SiC}$ implies the redistribution was due to the annealing out of a finite mobile point defect population which is indicative of an enhanced diffusion by ion implantation [38].

\subsubsection{SIMS Results from Polycrystalline 3C-SiC Diffusion Couples}

SIMS Ag depth profiles for $5 \times 10^{14}$ ions $/ \mathrm{cm}^{2}$ polycrystalline $3 \mathrm{C}-\mathrm{SiC}$ substrates exposed to isochronal conditions of $1500-1569^{\circ} \mathrm{C}$ for 10 hours are shown in Figure 7. The Ag concentration is observed to penetrate into the bulk $\mathrm{SiC}$ past the primary implantation peak with increasing penetration as a function of exposure temperature. Figure 8 shows a comparison of $5 \times 10^{14}$ ions $/ \mathrm{cm}^{2}$ polycrystalline $3 \mathrm{C}$ $\mathrm{SiC}$ substrates exposed to $1500^{\circ} \mathrm{C}$ for 10 and 20 hours with the AI condition. From Figure 8 minimal variation in the $\mathrm{Ag}$ concentration between the $1500^{\circ} \mathrm{C} 10$ and 20 hours exposures is observed suggesting the observed profile is due to similar enhanced $\mathrm{Ag}$ diffusion due to finite non-equilibrium point defects generated during implantation. Figure 9 shows the $\mathrm{Ag}$ concentration depth profiles for isothermal $5 \times 10^{14}$ ions $/ \mathrm{cm}^{2}$ polycrystalline $3 \mathrm{C}-\mathrm{SiC}$ substrates exposed to $1569^{\circ} \mathrm{C}$ for $5-20$ hours and indicates the $\mathrm{Ag}$ penetration into bulk SiC increases as a function of time. This observation suggests the Ag concentration "tail" extending into the bulk past the primary implantation peak is due to a thermal transport mechanism. A comparative Ag concentration penetration depth was determined at a reference Ag concentration of $2 \times 10^{16} \mathrm{at} / \mathrm{cm}^{3}$ in the Ag penetration "tail". The magnitude of the observed Ag penetration past the AI profile is approximately $0.19 \mu \mathrm{m}, 0.44 \mu \mathrm{m}$ and $0.66 \mu \mathrm{m}$ for $1500^{\circ} \mathrm{C}, 1535^{\circ} \mathrm{C}$, and $1569^{\circ} \mathrm{C}, 10$ hour exposures, respectively, while the $1625^{\circ} \mathrm{C} 1$ hour exposure indicated an Ag concentration penetration of $0.34 \mu \mathrm{m}$ past the AI profile. Evidence of thermal Ag diffusion is indicated by extended Ag penetration past the consistent $1500^{\circ} \mathrm{C} 10$ and 20 hour profiles. For the $1500^{\circ} \mathrm{C}$ profiles, the consistent profiles imply no Ag transport is measurable beyond the signature of the implantation-induced transport. Figure 10 shows a Ag dose comparison for polycrystalline $3 \mathrm{C}-\mathrm{SiC} 1 \times 10^{14} \mathrm{ions} / \mathrm{cm}^{2}$ and $5 \times 10^{14} \mathrm{ions} / \mathrm{cm}^{2} \mathrm{AI}$ and $1535^{\circ} \mathrm{C} 10$ hour exposures, the profiles indicate a similar Ag concentration penetration profile extending into the bulk $\mathrm{SiC}$ offset by the variation in independent AI profiles suggesting minimal implantation dose dependence. 
A reduction of the primary peak for Ag implanted concentration was noted for most exposures and this is consistent with previously reported observation of thermally exposed $\mathrm{Ag} / \mathrm{SiC}$ implantation diffusion couples and is expected to be due to loss to the implantation surface $[9,10,13,17]$. For the $1569^{\circ} \mathrm{C} 10$ hours and 20 hours exposures a peak shift skewed away from the implantation surface was observed. This was also reported by Friedland et al. [9] and was suggested to be due to grain boundary diffusion effects.

\subsubsection{Diffusion Analysis of Polycrystalline 3C-SiC Diffusion Couples}

For ion implantation diffusion experiments, the main implantation peak serves as a constant source approximation when the peak concentration is greater than the solubility limit, $S(T)$, of the system. A modified equation for diffusion dependence of ion implanted impurity species is presented in Equation 5. In Equation 5, $C_{o}$ is the concentration at which the impurity species extends into the bulk, $d_{o}$ is the depth at which the impurity concentration deviates from the implantation peak at $C_{o}, d$ is the depth at $C(d, t), t$ is time in seconds, and $D$ is the diffusion coefficient [52].

Equation 5: $C=C_{o} \operatorname{erfc}\left(\frac{d-d_{o}}{\sqrt{4 D t}}\right)$

The magnitude of the $\mathrm{Ag}$ concentration penetration "tail", $C_{o}$, was estimated by extrapolating a linear fit of the Ag concentration "tail" in the bulk to the primary implantation peak. Table 2 presents the magnitude for the observed $\mathrm{Ag}$ penetration, $C_{o}$, for each implantation sample.

Table 2: $C_{o}$ values for polycrystalline 3C-SiC diffusion profiles

\begin{tabular}{|c|c|c|c|c|}
\hline Time & Dose & $\mathbf{1 5 3 5}^{\circ} \mathbf{C}$ & $\mathbf{1 5 6 9}^{\circ} \mathbf{C}$ & $\mathbf{1 6 2 5}^{\circ} \mathbf{C}$ \\
\hline \multirow{3}{*}{ 1 hour } & $5 \times 10^{14}$ ions $/ \mathrm{cm}^{2}$ & - & - & $6.47 \pm 0.57 \times 10^{16} \mathrm{at}^{2} \mathrm{~cm}^{3}$ \\
\cline { 2 - 5 } & $1 \times 10^{14}$ ions $/ \mathrm{cm}^{2}$ & - & - & - \\
\hline \multirow{2}{*}{5 hours } & $5 \times 10^{14}$ ions $/ \mathrm{cm}^{2}$ & - & $6.33 \pm 0.83 \times 10^{16} \mathrm{at}^{2} \mathrm{~cm}^{3}$ & - \\
\cline { 2 - 6 } & $1 \times 10^{14}$ ions $/ \mathrm{cm}^{2}$ & - & - & - \\
\hline \multirow{2}{*}{$\mathbf{1 0}$ hours } & $5 \times 10^{14}$ ions $/ \mathrm{cm}^{2}$ & $6.13 \pm 0.43 \times 10^{16}{\mathrm{at} / \mathrm{cm}^{3}}^{3}$ & $6.26 \pm 0.69 \times 10^{16} \mathrm{at} / \mathrm{cm}^{3}$ & - \\
\hline
\end{tabular}




\begin{tabular}{|c|c|c|c|c|}
\hline & $1 \times 10^{14}$ ions $/ \mathrm{cm}^{2}$ & $4.81 \pm 0.43 \times 10^{16} \mathrm{at} / \mathrm{cm}^{3}$ & - & - \\
\hline \multirow{2}{*}{20 hours } & $5 \times 10^{14}$ ions $/ \mathrm{cm}^{2}$ & - & $6.03 \pm 0.70 \times 10^{16} \mathrm{at} / \mathrm{cm}^{3}$ & - \\
\hline & $1 \times 10^{14}$ ions $/ \mathrm{cm}^{2}$ & - & - & - \\
\hline
\end{tabular}

Diffusion coefficients for $\mathrm{Ag}$ in polycrystalline $3 \mathrm{C}-\mathrm{SiC}, D^{A g}$, were estimated for the exposures at and above $1535^{\circ} \mathrm{C}$ by numerically solving Equation 5 using the $C_{o}$ values in Table 2. Estimated values for $D^{A g}$ from the SIMS profiles are presented in Table 3. Fitting the $D^{A g}$ to an Arrhenius relationship, Equation 1, using a least squares fit equates to an activation energy, $Q$, of $5.89 \pm 0.99 \mathrm{eV}$ and a preexponential term, $D_{o}$ of $2.08 \times 10^{-1} \mathrm{~m}^{2} / \mathrm{s}$. The range of the pre exponential term error is $4.04 \times 10^{-4}$ to $1.07 \times 10^{2} \mathrm{~m}^{2} / \mathrm{s}$. Error is estimated from the standard deviation of the linear regression fit.

Table 3: Estimated Ag diffusion coefficients in SiC $\left(D^{A g}\right)$ from SIMS diffusion profiles

\begin{tabular}{|c|c|c|c|c|}
\hline Time & Dose & $1535^{\circ} \mathrm{C}$ & $1569^{\circ} \mathrm{C}$ & $1625^{\circ} \mathrm{C}$ \\
\hline \multirow{2}{*}{1 hour } & $5 \times 10^{14}$ ions $/ \mathrm{cm}^{2}$ & - & - & $5.17 \pm 0.56 \times 10^{-17} \mathrm{~m}^{2} / \mathrm{s}$ \\
\hline & $1 \times 10^{14}$ ions $/ \mathrm{cm}^{2}$ & - & - & - \\
\hline \multirow{2}{*}{5 hours } & $5 \times 10^{14}$ ions $/ \mathrm{cm}^{2}$ & - & $1.40 \pm 0.42 \times 10^{-17} \mathrm{~m}^{2} / \mathrm{s}$ & - \\
\hline & $1 \times 10^{14}$ ions $/ \mathrm{cm}^{2}$ & - & - & - \\
\hline \multirow{2}{*}{10 hours } & $5 \times 10^{14}$ ions $/ \mathrm{cm}^{2}$ & $9.72 \pm 8.63 \times 10^{-18} \mathrm{~m}^{2} / \mathrm{s}$ & $1.27 \pm 0.19 \times 10^{-17} \mathrm{~m}^{2} / \mathrm{s}$ & - \\
\hline & $1 \times 10^{14}$ ions $/ \mathrm{cm}^{2}$ & $8.19 \pm 1.92 \times 10^{-18} \mathrm{~m}^{2} / \mathrm{s}$ & - & - \\
\hline \multirow{2}{*}{20 hours } & $5 \times 10^{14}$ ions $/ \mathrm{cm}^{2}$ & - & $1.41 \pm 0.15 \times 10^{-17} \mathrm{~m}^{2} / \mathrm{s}$ & - \\
\hline & $1 \times 10^{14}$ ions $/ \mathrm{cm}^{2}$ & - & - & - \\
\hline \multicolumn{2}{|c|}{ Average } & $8.95 \times 10^{-18} \mathrm{~m}^{2} / \mathrm{s}$ & $1.36 \times 10^{-17} \mathrm{~m}^{2} / \mathrm{s}$ & $5.17 \times 10^{-17} \mathrm{~m}^{2} / \mathrm{s}$ \\
\hline \multicolumn{2}{|c|}{ Error } & $\pm 4.42 \times 10^{-18} \mathrm{~m}^{2} / \mathrm{s}$ & $\pm 1.63 \times 10^{-18} \mathrm{~m}^{2} / \mathrm{s}$ & $\pm 5.62 \times 10^{-18} \mathrm{~m}^{2} / \mathrm{s}$ \\
\hline
\end{tabular}


SIMS depth profiling in the polycrystalline 3C-SiC substrates gives rise to the possibility that the observed Ag penetration is due to SIMS artifacts from preferential sputtering and roughness effects. The peak-to-valley roughness of the SIMS crater surface is an indication of the magnitude of the crater surface roughness. Peak-to-valley roughness was measured by optical profilometery to be $0.05 \pm 0.02 \mu \mathrm{m}$. This equates to penetration depths approximately $4-13 x$ greater than the peak-to-valley roughness as measured at the reference $\mathrm{Ag}$ concentration of $2 \times 10^{16} \mathrm{at} / \mathrm{cm}^{3}$ past the $\mathrm{AI}$ profile for $1500-1625^{\circ} \mathrm{C}$. Additionally, the peak-to-valley roughness did not correlate with measured Ag concentration penetration differences observed in the isothermal $1569^{\circ} \mathrm{C}$ comparison, implying that the variation in observed $\mathrm{Ag}$ penetration is not primarily due to a SIMS artifact.

Additional caution is noted for the diffusion analysis in this study as the contributions of enhanced diffusion from annealing of excess point defects during the initial stages of $\mathrm{Ag}$ defect diffusion are unknown and will likely influence the observed diffusion. Furthermore, secondary diffusion phenomena associated with peak broadening may also influence the diffusion analysis of $C_{o}$. The contribution of these effects on the diffusion analysis error is not explicitly known. To mitigate concerns about the influence of implantation effects, higher temperatures should be investigated to drive diffusion lengths past the primary implantation peak and the magnitude of the Ag penetration to concentrations above the influence of the enhanced Ag diffusion and SIMS detection limits.

\subsubsection{Discussion of Diffusion in Polycrystalline 3C-SiC: Role of Microstructure}

Comparison of the change in $\mathrm{Ag}$ concentration past the primary implantation peak between the single crystal $4 \mathrm{H}-\mathrm{SiC}$ and polycrystalline $3 \mathrm{C}-\mathrm{SiC}$ substrates suggests polycrystalline $3 \mathrm{C}-\mathrm{SiC}$ accommodates excess $\mathrm{Ag}$ and facilitates impurity diffusion into bulk SiC. Ideally, the single crystal 4H$\mathrm{SiC}$ substrate serves to isolate lattice diffusion contributions while the polycrystalline $3 \mathrm{C}$-SiC substrate serves to mimic the TRISO fuel layer by introducing GB diffusion to contribute to Ag transport.

The absence of $\mathrm{Ag}$ extending into bulk $\mathrm{SiC}$ in the single crystal $4 \mathrm{H}-\mathrm{SiC}$ substrates suggest $\mathrm{Ag}$ is not accommodated in single crystal $\mathrm{SiC}$ above $1 \times 10^{15} \mathrm{at} / \mathrm{cm}^{3}$, while an extension of the $\mathrm{Ag}$ concentration 
is observed at approximately $4-7 \times 10^{16}$ at $/ \mathrm{cm}^{3}$ for the polycrystalline $3 \mathrm{C}-\mathrm{SiC}$ substrates. The single crystal $4 \mathrm{H}-\mathrm{SiC}$ substrates indicate that implanted defects are annealed out after $1500^{\circ} \mathrm{C} 10$ hours. The extension of $\mathrm{Ag}$ into the bulk of the polycrystalline $3 \mathrm{C}-\mathrm{SiC}$ and similar diffusion profiles for the polycrystalline $3 \mathrm{C}$ $\mathrm{SiC} 5 \times 10^{14}$ ions $/ \mathrm{cm}^{2} 1500^{\circ} \mathrm{C} 10$ and 20 hours exposures suggests GBs act as Ag impurity sinks to the mobile implanted Ag defects during the initial stages of the thermal annealing, while the presence of GBs facilitates measurable impurity diffusion above $1535^{\circ} \mathrm{C}$. To the author's knowledge no experimental values of the solubility limits of $\mathrm{Ag}$ in single crystal or polycrystalline $\mathrm{SiC}$ are presented in literature. Solubility limits, $S(T)$, for impurities with atomic numbers greater than 37 , exhibit a maximum solubility of $2.5 \times 10^{17} \mathrm{at} / \mathrm{cm}^{3}$ at temperatures greater than $2150^{\circ} \mathrm{C}$ [29]. The observation of $S(T)<1 \times 10^{15} \mathrm{at} / \mathrm{cm}^{3}$ for the single crystal $4 \mathrm{H}-\mathrm{SiC}$ substrate follows this trend. The presence of GBs likely accounts for an increase in the $S(T)$ of the system as $\mathrm{Ag}$ is expected to strongly segregate to GBs with an estimated GB segregation factor, $s$, of approximately $1 \times 10^{8}$ at $1500^{\circ} \mathrm{C}$ where $s$ is defined as the ratio of the impurity concentration at the GB to the impurity concentration in the lattice [14]. This implies most Ag is expected to be segregated to GBs. Electron backscatter diffraction analysis of the polycrystalline 3C-SiC substrate in this study estimated the total grain boundary volume fraction is calculated to be approximately $4 \times 10^{-4}$. Under a bounding condition of complete GB saturation, an upper estimate for $S(T)$ of approximately $4 \times 10^{19}$ at $/ \mathrm{cm}^{3}$ is possible. The measured $C_{o}$ for the observed $\mathrm{Ag}$ concentration penetration correlates to $\mathrm{Ag} \mathrm{GB}$ concentration of approximately 0.1 at $\%$ and a bulk Ag concentration $<<1 \times 10^{15} \mathrm{at} / \mathrm{cm}^{3}$, for $s \approx 1 \times 10^{8}$. For both scenarios the peak implanted Ag concentration is above the expected $S(T)$ of the $4 \mathrm{H}-\mathrm{SiC}$ and $3 \mathrm{C}-\mathrm{SiC}$ systems implying that the constant source approximation assumed in Equation 5 was satisfied.

The presence of GBs implies that the measured Ag penetration in $3 \mathrm{C}-\mathrm{SiC}$ is due to GB diffusion and is more significant than impurity lattice diffusion. This is supported by experimental observations which suggest C GB self-diffusion in polycrystalline 3C-SiC is 5-6 orders of magnitude faster than lattice diffusion [40] and ab initio results which suggest $D^{A g}$ along $\Sigma 3$ GBs is greater than 10 orders of magnitude larger than lattice diffusion [14]. Again, this suggests the observed diffusion in polycrystalline 3C-SiC is due primarily to GB diffusion, however, other microstructural variables may contribute to the 
observed diffusion, including differences in dislocation density, stacking fault density, and extrinsic defect populations. The presence of stacking faults (SF) and GBs are confirmed in the BF-TEM analysis of the polycrystalline 3C-SiC substrates (Figure 1), while no such features are observed in the BF-TEM analysis of the single crystal $4 \mathrm{H}-\mathrm{SiC}$ substrates (Figure 2).

\subsection{Comparison of Ag Diffusion Energetics with Literature}

Table 4 shows a comparison of the pre-exponential term, $D_{o}$, and activation energy, $Q$ from ion implantation studies $[9,10,16]$, computational studies $[14,15,26]$, release from TRISO fuel $[4,5,18-24]$ and self-diffusion in of Si and C in polycrystalline 3C-SiC [40,41]. Figure 11 graphically illustrates the magnitude of the reported diffusion coefficients.

Table 4: $D_{o}$ and $Q$ values for $\mathrm{Ag} / \mathrm{SiC}$ diffusion and Si and $\mathrm{C}$ tracer self-diffusion from ion implantation, computational simulations, and TRISO release.

\begin{tabular}{|c|c|c|c|c|c|}
\hline Type & Mechanism & $D_{o}\left(m^{2} / s\right)$ & $Q(e V)$ & Note & Ref. \\
\hline This work & $G B^{*}$ & $2.08 \times 10^{-1}$ & $5.89 \pm 0.99$ & *Exact mechanism unknown & - \\
\hline Implantation & $G B$ & $4.30 \times 10^{-12}$ & 2.50 & & [9] \\
\hline Implantation & Lattice & \multicolumn{2}{|c|}{$D<1 \times 10^{-21}$} & Upper bound $\left(1400^{\circ} \mathrm{C}\right)$ & [9] \\
\hline Implantation & $G B$ & $2.40 \times 10^{-9}$ & 3.43 & & [10] \\
\hline Implantation & --- & \multicolumn{2}{|c|}{$D<5 \times 10^{-21}$} & Upper bound $\left(1500^{\circ} \mathrm{C}\right)$ & [16] \\
\hline Simulation & Lattice & $6.30 \times 10^{-8}$ & 7.88 & Fastest calc. mechanism & [26] \\
\hline Simulation & $G B$ & $1.60 \times 10^{-7}$ & 3.95 & $\begin{array}{l}\text { (210) } \Sigma 3 \text { tilt } G B, \text { fastest } \\
\text { mechanism along [01] }\end{array}$ & [14] \\
\hline Simulation & $G B$ & - & $3.35 \pm 0.25$ & (120) antiphase $\Sigma 5$ tilt $G B$ & [15] \\
\hline TRISO Release & - & \multicolumn{2}{|c|}{$D>1 \times 10^{-16}$} & Lower Bound $\left(1500^{\circ} \mathrm{C}\right)$ & [4] \\
\hline TRISO Release & - & $6.76 \times 10^{-9}$ & 2.21 & & [5] \\
\hline
\end{tabular}




\begin{tabular}{|c|c|c|c|c|c|}
\hline TRISO Release & - & $4.50 \times 10^{-9}$ & 2.26 & & {$[18]$} \\
\hline TRISO Release & - & $9.60 \times 10^{-6}$ & 4.22 & "Good SiC" & {$[19]$} \\
\hline TRISO Release & - & $4.50 \times 10^{-5}$ & 4.16 & "Medium SiC" & {$[19]$} \\
\hline TRISO Release & - & $2.50 \times 10^{-3}$ & 4.24 & "Poor SiC" & {$[19]$} \\
\hline TRISO Release & - & $3.60 \times 10^{-9}$ & 2.23 & & {$[20]$} \\
\hline TRISO Release & - & $6.80 \times 10^{-11}$ & 1.83 & & {$[21,22]$} \\
\hline TRISO Release & - & $3.50 \times 10^{-10}$ & 2.21 & & {$[23]$} \\
\hline TRISO Release & - & $1.14 \times 10^{-13}$ & 1.13 & C Self-Diff. & {$[40]$} \\
\hline Tracer & Lattice & $2.62 \pm 1.83 \times 10^{4}$ & $8.72 \pm 0.14$ & C Self-Diff. & {$[40]$} \\
\hline Tracer & GB & $4.44 \pm 2.03 \times 10^{3}$ & $5.84 \pm 0.09$ & Si Self-Diff & {$[41]$} \\
\hline Tracer & Lattice & $8.36 \pm 1.99 \times 10^{3}$ & $9.45 \pm 0.05$ & & \\
\hline
\end{tabular}

The Si and C lattice self-diffusion coefficients and the C GB self-diffusion coefficient bracket the estimated $D^{A g}$ from this study, while the calculated activation energy of $5.89 \pm 0.99 \mathrm{eV}$ is similar to that of C GB self-diffusion [40]. This comparison suggests a similar mechanism may be active for the observed Ag diffusion. Additionally, the magnitude of $D^{A g}$ in this work is approximately one order of magnitude greater than the reported effective $D^{A g}$ for GB diffusion along $\Sigma 3$ GBs [14]. The observed deviation may be accounted for in that diffusion along $\Sigma 3 \mathrm{GBs}$ is expected to be a limiting case relative to diffusion along general GBs. With $\Sigma 3$ GBs representing limiting GB diffusion pathways, contributions from additional GB types, namely high angle grain boundaries, have been shown to increase the effective $D^{A g}$ [53]. An increase in the effective $D^{A g}$ for GB dependent diffusion with the inclusion of additional GB types is supported by the findings of Rabone et al. [15] who report a $D^{A g}$ along $\Sigma 5$ GBs approximately two to three orders of magnitude greater than the fastest mechanism along the $\Sigma 3$ GB [14]. Because the $D^{A g}$ measured in this work is an average of all GB types present in the SiC layer, the inclusion of general 
GBs would be expected to increase the effective $D^{A g}$ over the calculated $D^{A g}$ for the $\Sigma 3 \mathrm{~GB}$. These observations give additional validation to the measured Ag diffusion being dominated by GB diffusion.

The root of the deviation in $Q$, between the experimental and GB diffusion simulation results $[14,15]$ is not explicitly known. The variation may be accounted for by the influence of microstructural defects (such as defect trapping, GB segregation, and GB character effects), implantation effects, and the contributions from multiple potential contributing diffusion mechanisms (dislocations, SFs, GBs). The cumulative influence of these effects is captured by the SIMS depth profiling technique employed in this study. Anisotropy effects may also contribute to the variation as the reported $Q$ for $\mathrm{Ag}$ diffusion along the $\Sigma 3 \mathrm{~GB}$ is reported to vary as a function of direction along the GB plane, with $Q_{\text {eff. }}$ for the fastest mechanism along the [111] direction equal to $7.56 \mathrm{eV}$ compared to $3.95 \mathrm{eV}$ for the fastest mechanism along the [011] direction [14]. Additionally, in this work diffusion analysis at short thermal exposures may be influenced by the initial rapid irradiation enhanced diffusion from the annealing out of ion implantation induced defects as observed in the single crystal $4 \mathrm{H}-\mathrm{SiC}$ conditions. This effect may lead to an overestimation of $D^{A g}$ as the depth profile may be dominated by the initial rapid enhanced diffusion at short time scales before thermal diffusion dominates. This effect would also influence the magnitude of $Q$, leading to a possible elevated value in this study, as the $1625^{\circ} \mathrm{C} 1$ hour exposure was the only condition with a "short thermal exposure time".

\subsubsection{Comparison of Diffusion Energetics with TRISO Fuel Release}

The reported activation energies, $Q$, for TRISO fuel release range from 1.13-2.26 eV [4,5,18,2024], as presented in Table 4. The work by Bullock [19] represents a deviation from the historical release data and reports a $Q$ ranging from $4.16-4.24 \mathrm{eV}$ with $D_{o}$ varying from $9.60 \times 10^{-6}$ to $2.50 \times 10^{-3} \mathrm{~m}^{2} / \mathrm{s}$ based on the perceived quality of the $\mathrm{SiC}$ layer, as significant variation in fission product release was measured in out-of-pile release studies for particles with varying TRISO layer construction and kernel compositions. The magnitude of the $D^{A g}$ from the Bullock study spans the régime associated with historical TRISO release data for "Poor SiC" and also presents $D^{A g}$ approximately two orders of 
magnitude lower than historical TRISO release data for "Good SiC". Nabielek et al. [5] also noted an effect of SiC layer quality on $\mathrm{Ag}$ release behavior with lower effective $D^{A g}$ measured for release from "Good" SiC as well as reporting a variation in in-pile and out-of-pile release behavior. Bullock postulated that the out-of-pile elevated temperature exposures led to an annealing out of the irradiation induced point defects, presenting a SiC layer more representative of unirradiated $\mathrm{SiC}$ [19]. The annealing out of irradiation induced defects is likely not the sole contributing factor to the observed variation between the Bullock study [19] and other historical studies, as the $D^{A g}(Q=2.26 \mathrm{eV})$ reported by Amian et al. [18] was also reported for out-of-pile release. The historical release data suggests the $D^{A g}$ is dependent on kernel composition, $\mathrm{SiC}$ quality, analysis approach, and irradiation conditions.

The variation in magnitude and energetics between TRISO release studies and the surrogate systems suggest the observed diffusion responsible for release in TRISO fuel is augmented relative to the diffusion observed in surrogate systems. The magnitude of reported $D^{A g}$ in this work is approximately one to three orders of magnitude lower relative to the reported $D^{A g}$ from historic TRISO fuel release, and other surrogate studies report similar deviations in magnitude of measured $D^{A g}[9,10,14,15]$. The difference in reported diffusion coefficients and energetics implies a significant variation between diffusion behavior of the observed diffusion in TRISO fuel and the observed diffusion studied in surrogate systems. A first order approximation attributes the observed discrepancies to the inherently complex irradiation effects present TRISO fuel service.

In this work, enhanced $\mathrm{Ag}$ diffusion was observed in single crystal $4 \mathrm{H}-\mathrm{SiC}$ under conditions expected to be interstitial rich, while the implantation enhanced diffusion was observed to be limited in régimes with excess vacancies and high interstitial sink densities. The variation in behavior is perceived to be dependent on the nature of non-equilibrium point defects and defect sink density. The microstructure of neutron and self-ion irradiated $\mathrm{SiC}$ varies as a function of temperature and dose, with a transition from black spot defects and small dislocation loops, to Frank faulted loops, to large loops, network dislocations, and voids with increasing temperature [54]. At elevated temperatures, approximately $1200^{\circ} \mathrm{C}$, the defect density decreases with a corresponding mean defect size increase [55]. 
This suggests a complex microstructure with varying defect sink densities and point defects populations exists over the life of the TRISO irradiation.

STEM analysis of the SiC layer in irradiated TRISO fuel particles identified fission products segregated to nano-scale features in the interior of $\mathrm{SiC}$ grains [56], suggesting diffusion of fission products into the $\mathrm{SiC}$ grain interior. A comprehensive understanding of the residual point defects and irradiated $\mathrm{SiC}$ microstructure is not fully presented for the irradiated TRISO SiC in Ag release studies. However, this study indicates that parallels may exist between the observed implantation enhanced Ag diffusion and Ag diffusion measured from TRISO fuel release. This implies the potential for enhanced lattice diffusion to contribute to Ag release under irradiation conditions where excess non-equilibrium point defects are present and able to contribute to diffusion.

The suggested GB diffusion in polycrystalline $3 \mathrm{C}$-SiC presents an alternative or co-operative mechanism to describe the deviation between TRISO release and surrogate systems. The comparison of single crystal $4 \mathrm{H}-\mathrm{SiC}$ and polycrystalline $3 \mathrm{C}-\mathrm{SiC}$ implantation samples confirms $\mathrm{Ag}$ segregates to $\mathrm{GBs}$ and because point defects are stable in GBs the same opportunity for irradiation-enhanced diffusion exists. van Rooyen et al. [56] have reported STEM analysis of the SiC layer in irradiated TRISO fuel particle that retained a high level of Ag and have identified Ag segregated to SiC grain boundaries at the IPyC/SiC interface [56]. This suggests $\mathrm{SiC}$ grain boundaries play a role in accommodating $\mathrm{Ag}$ and may serve as diffusion pathways. Additionally, modification of the local GB structure through the nucleation of cavities at GBs has been observed for Si self-ion irradiations [54]. Similar modification of the GB structure in the SiC layer of TRISO fuel may influence the effective diffusion length scale for Ag release. These effects may result in the observed higher $D^{A g}$ for TRISO release relative to surrogate experiments.

\section{Summary}

The use of SIMS for depth profiling of $\mathrm{Ag} / \mathrm{SiC}$ ion implantation diffusion couples provides an increased dynamic range allowing for the identification of multiple diffusion régimes not previously observed. Ag diffusion was observed to be active via enhanced diffusion of implantation-induced defects in the single crystal $4 \mathrm{H}-\mathrm{SiC}$ single crystal substrates under perceived interstitial rich conditions, while 
thermal diffusion past the primary implantation peak was measured in the polycrystalline $3 \mathrm{C}-\mathrm{SiC}$ substrates. The comparison of single crystal $4 \mathrm{H}-\mathrm{SiC}$ and polycrystalline $3 \mathrm{C}-\mathrm{SiC}$ diffusion couples confirm that GBs act as Ag impurity sinks and suggest GB diffusion contributes to the observed diffusion in the polycrystalline 3C-SiC substrate. The magnitude and energetics of the suggested GB diffusion implies impurity diffusion in annealed ion implanted polycrystalline 3C-SiC does not account for the measured Ag release from TRISO fuel determined from Ag release experiments. This, coupled with the measured implantation-enhanced diffusion in single crystal 4H-SiC, implies that irradiation effects likely contribute the observed Ag release. These observations provide additional confirmation of active Ag diffusion in polycrystalline 3C-SiC and present new insights on enhanced Ag diffusion in single crystal 4H-SiC suggesting irradiation enhanced lattice diffusion may also contribute to Ag release in the TRISO fuel system.

\section{Acknowledgements:}

The authors would like to thank Prof. Izabela Szlufarska and Prof. Dane Morgan for their critical discussions concerning the topic of Ag diffusion ins SiC. The authors would also like to thank Dr. Ovidiu Toader for conducting the Ag implantations at the MIBL. A portion of this research utilized National Science Foundation (NSF) supported shared facilities at the University of Wisconsin. This work supported by the US DOE, Office of Nuclear Energy Nuclear Energy University Program (NEUP), award no. 11-2988 and by the US DOE, Office of Nuclear Energy under DOE Idaho Operations Office Contract DE-AC07-051D14517, as part of an ATR-NSUF experiment. 


\section{References:}

[1] L.L. Snead, T. Nozawa, Y. Katoh, T. S. Byun, S. Kondo, and D. A. Petti, J. Nucl. Mater. 371, 329377 (2007).

[2] D. Petti, J. Maki, J. Hunn, P. Pappano, C. Barnes, J. Saurwein, S. Nagley, J. Kendall, and R. Hobbins, JOM, 62, 9, 62-66 (2010).

[3] P.A. Demkowicz, J.D. Hunn, R.N. Morris, J.M. Harp, P.L. Winston, C.A. Baldwin, and F.C. Montgomery, "Preliminary results of post-irradiation examination of the AGR-1 TRISO fuel compacts," Proceedings of the 6th International Topical Meeting on High Temperature Reactor Technology, Tokyo, Japan, October 28-November 1, 2012, HRT2012 (2012).

[4] P.E. Brown, and R.L. Faircloth, J. Nucl. Mater. 5929 (1976).

[5] H. Nabielek, P.E. Brown, and P. Offermann, Nucl. Technol. 35483 (1977).

[6] I.J. van Rooyen, M.L. Dunzik-Gougar, and P.M. van Rooyen, Nucl. Eng. Des., 271, 180-188, (2014).

[7] J.B. Malherbe, J. Phys. D: Appl. Phys. 46 (2013).

[8] D. A. Petti, J. Buongiorno, J. T. Maki, R. R. Hobbins and G. K. Miller, Nucl. Eng. Des., 222, 2-3 (2003).

[9] E. Friedland, J.B. Malherbe, N.G. van der Berg, T. Hlatshwayo, A.J. Botha, E. Wendler, and W. Wesch, J. Nucl. Mater., 389, 2, 326-331 (2009).

[10] E. Friedland, N.G. vander Berg, J.B. Malherbe, J.J. Hancke, J.R.N. Barry, E. Wendler, and W. Wesch, J. Nucl. Mater. 410, 24 (2011).

[11] E. López-Honorato, D. Yang, J. Tan, P.J. Meadows, and P. Xiao, J. Am. Ceram. Soc. 93, 3076 (2010).

[12] J.H. Neethling, J.H. O’Connell, and E.J. Olivier, Nucl. Eng. Des., 251, 230 (2012).

[13] T.T. Hlatshwayo, J.B. Malherbe, N.G. van der Berg, L.C. Prinsloo, A.J. Botha, E. Wendler, and W.E. Wesch, Nucl. Instrum. Methods Phys. Res. B 274, 120 (2012).

[14] S. Khalil, N. Swaminathan, D.,Shrader, A.J.,Heim, D.D. Morgan, and I. Szlufarska, Phys. Rev. B 84, 214104 (2011).

[15] J. Rabone, E. López-Honorato, and P. Van Uffelen, J. Phys. Chem. A 118, 915-926 (2014).

[16] H.J. MacLean, R.G. Ballinger, L.E. Kolaya, S.A. Simonson, N. Lewis, and M.E. Hanson, J. Nucl. Mater. 357, 31 (2006).

[17] X.Y. Xiao, Y. Zhang, L.L.Snead, V. Shutthananddan, H.Z. Xue, and W.J. Weber, J. Nucl. Mater. $420,123-130$ (2012). 
[18] W. Amian and D. Stöver, Nucl. Tech., 61, 3 (1983).

[19] R.E.Bullock, J. Nucl. Mater., 125, 304-319 (1984).

[20] R. Moormann and K. Verfondern, "Methodikumfassender probabilistischer Sicherheitsanalysen fur zukunftige HTR-Anlagenkonzepte-Ein Statusbericht Band 3: Spaltproduktfreisetzung Report," Jul-Spez-388/Vol. 3, Research Center Julich (1986).

[21] K. Fukuda et al. "Research and development of HTGR fuels Report," JAERIM89-007 (1989).

[22] K. Minato, "Diffusion coefficients of fission products in UO2, PyC, SiC, graphite matrix and IG110 graphite, unification of coated particle performance models and fission product transport data for the HTR IAEA Technical Workshop," (Julich, Germany) (1991).

[23] A.S. Chernikov, et al. "Fission Product diffusion in fuel element materials for HTGR, Fission product release and transport in gas-cooled reactors," (Proc. IAEA Specialists Meeting, Berkley, 1985), IAEA IWGGCR/13, Vienna 170-181. (1986).

[24] J.J. van der Merwe, J. Nucl. Mater. 395, 99 (2009).

[25] T.T. Hlatshwayo, J.B. Malherbe, N.G. van der Berg, A.J. Botha, and P. Chakraborty, Nucl. Instrum. Methods Phys. Res. B 273, 61 (2012).

[26] D. Shrader, S.M. Khalil, T. Gerczak, T.R. Allen, A.J. Heim, I. Szlufarska, and D. Morgan, J. Nucl. Mater., 408, 257-271 (2011).

[27] G. Méric de Bellefon, and B.D. Wirth, J. Nucl. Mater. 413, 122 (2011).

[28] W. Jiang, W.J. Weber, V. Shutthanandan, L. Li, and S., Thevuthasan, Nucl. Instrum. Methods Phys. Res. B 219-20642 (2004).

[29] O. Madelung, U. Rössler, and M. Schulz, (editors), "LB Volumes III/22B-41A2b: silicon carbide (SiC), solubility of impurities." Springer Materials - The Landolt-Börnstein Database

[30] C. M. Zetterling, Process Technology for Silicon Carbide Devices. EMIS processing series, no. 2, INSPEC, IEE, UK, 2002.

[31] C.A. Baldwin, J.D. Hunn, R.N. Morris, F.C. Montgomery, G.W.C. Silva, and P.A. Demkowicz, Nucl. Eng. Des., 271, 131-141 (2014).

[32] N. Eustathopoulos, M. G. Nicholas, and B. Drevet, "Wettability at High Temperatures," Elsevier, Oxford, UK (1999).

[33] T. Troffer, M. Schadt, T. Frank, H. Itoh, G. Pensl, J. Heindl, H. P. Strunk, and M. Maier, Phys. Stat. Sol. (a), 162, 1, 277-298 (1997).

[34] H. Bracht, N.A. Stolwijk, M. Laube, and G. Pensl, Appl. Phys. Lett. 77, 3188 (2000).

[35] T.J. Gerczak, G. Zheng, K.G. Field, and T.R. Allen, J. Nucl. Mater., 456, 281-286 (2015).

[36] Y. Zhang, I. Bae, K. Sun, C. Wang, M. Ishimary, Z. Zhu, W. Jiang, and W.J. Weber, J. Appl. Phys., 105, 104901 (2009). 
[37] A.Y. Kuznetsov, M. Janson, A. Hallen, B.G. Svensson, and A. Nylandsted Larsen, Nucl. Instrum. Methods Phys. Res. B, 148, 279-283 (1999).

[38] P.A. Stolk, H.J. Gossmann, D.J. Eaglesham, D.C. Jacobson, C.S. Rafferty, G.H. Gillmer, M. Jaraiz, J.M. Poate, H.S. Luftman, and T.E. Haynes, J. Appl. Phys. 81 (9) (1997).

[39] M. Bockstedte, M. Heid, A. Mattausch, and O. Pankratov, Materials Science Forum, 389-393, 471476 (2002).

[40] M.H. Hon, and R.F. Davis, J. Mater. Sci. 14, 2411-2421 (1979).

[41] M.H. Hon, R.F. Davis, and D.E. Newbury, J. Mater. Sci., 15, 2073-2080 (1980).

[42] J.M. Lento, L. Torpo, T.E.M. Staab, and R.M. Nieminen, J. Phys.: Condens. Matter., 16, 1053-1060 (2004).

[43] A. Mattausch, M. Bockstedte, and O. Pankratov, Materials Science Forum, 353-356, 323-326 (2001).

[44] P. Lévêque, H. Kortegaard Nielsen, P. Pellegrino, A. Hallén, B. G. Svensson, A. Yu. Kuznetsov, J. Wong-Leung, C. Jagadish, and V. Privitera, J. Appl. Phys. 93, 871 (2003).

[45] P. Pellegrino, P. Lévêque, J. Wong-Leung, C. Jagadish, and B. G. Svensson, Appl. Phys. Lett. 78, 3442 (2001).

[46] L. Pelaz, G. H. Gilmer, M. Jaraiz, S. B. Herner, H.-J. Gossmann, D. J. Eaglesham, G. Hobler, C. S. Rafferty, and J. Barbolla, Appl. Phys. Lett. 73, 1421 (1999).

[47] Y. M. Gueorguiev, R. Kögler, A. Peeva, A. Mücklich, D. Panknin, R. A. Yankov, and W. Skorupa, J. Appl. Phys. 88, 5645 (2000).

[48] R. Kögler, A. Peeva, A. Lebedev, M. Posselt, W. Skorupa, G. Özelt, H. Hunter, and M. Behar, J. Appl. Phys. 94, 3834 (2003).

[49] Y. M. Gueorguiev, R. Kögler, A. Peeva, D. Panknin, A. Mücklich, R. A. Yankov, and W. Skorupa, Appl. Phys. Lett. 75, 3467 (1999).

[50] N.A. Stolwijk, B. Schuster, J. Holzl, H. Mehrer, W. Frank, Physica 116B, 335-342 (1983).

[51] H.S. Chao, S.W. Crowder, P.B. Griffin, J.D. Plummer, J. Appl. Phys. 79 (5), 1 (1996).

[52] S. M. Myers, J. Vac. Sci. Technol. 15, 1650 (1978).

[53] T. Fujita, Z. Horita, and T.G. Langdon, Mater. Sci. Eng., A. 371, 241-250 (2004).

[54] Y. Katoh, N. Hashimoto, S. Kondo, L.L. Snead, and A. Kohyama, J. Nucl. Mater. 351, 228 (2006).

[55] S. Kondo, Y. Katoh, and L.L. Snead, J. Nucl. Mater. 386-388, 22 (2007).

[56] I.J. van Rooyen, Y.Q. Wu, and T.M. Lillo, J. Nucl. Mater. 446, 178-186 (2014). 
Tables and Figures:
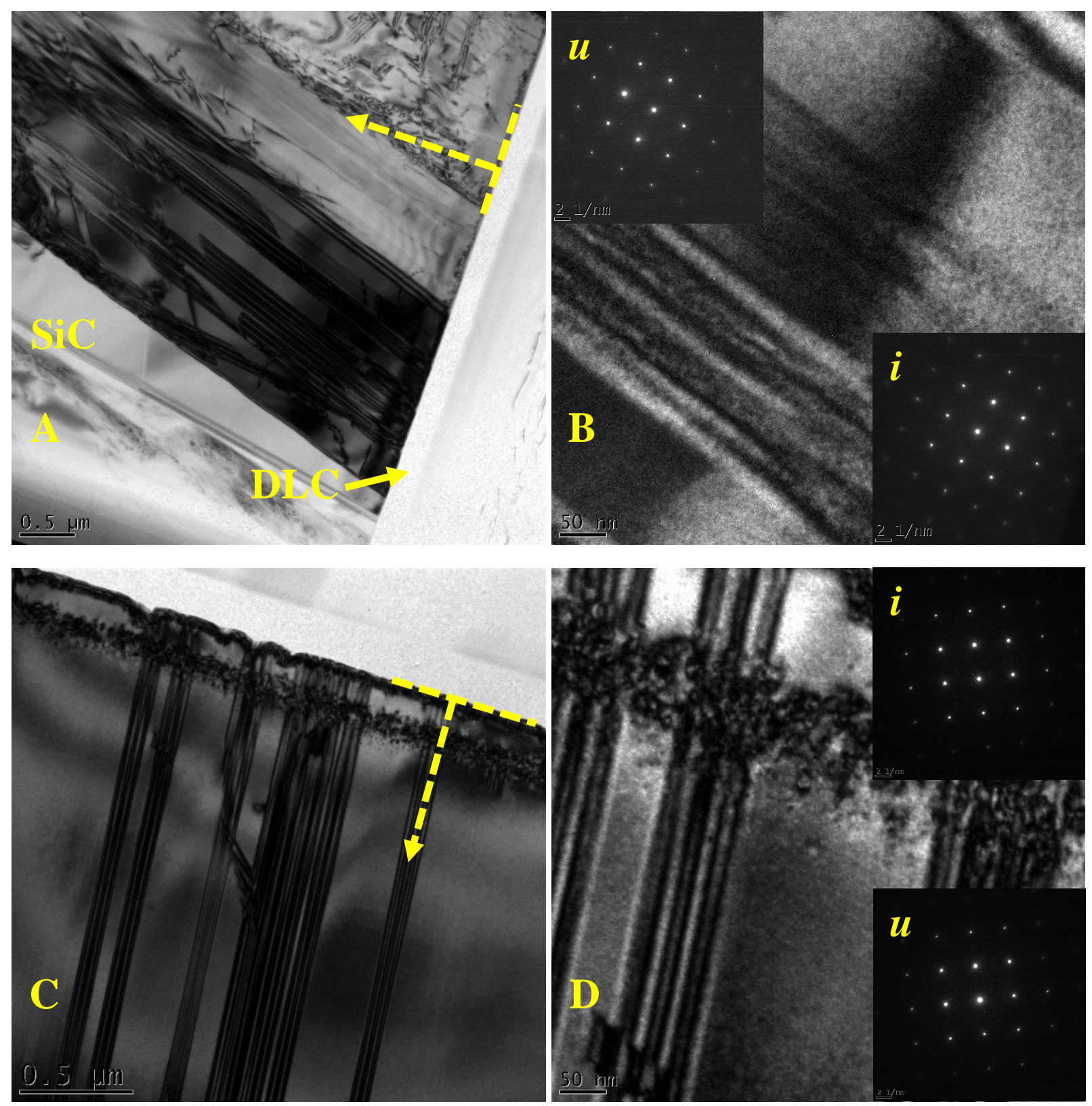

Figure 1: BF TEM micrographs of polycrystalline $3 \mathrm{C}-\mathrm{SiC} 5 \times 10^{14}$ ions $/ \mathrm{cm}^{2} \mathrm{AI}(\mathrm{A}-\mathrm{B})$ and $1569^{\circ} \mathrm{C} 20$ hours (C-D) conditions, inset SAD of (200) zone axis, dashed line indicates implantation surface while arrow indicates direction implantation direction, $i$ ) indicates $\mathrm{SAD}$ from implanted region, $u$ ) indicates $\mathrm{SAD}$ from undamaged region. 

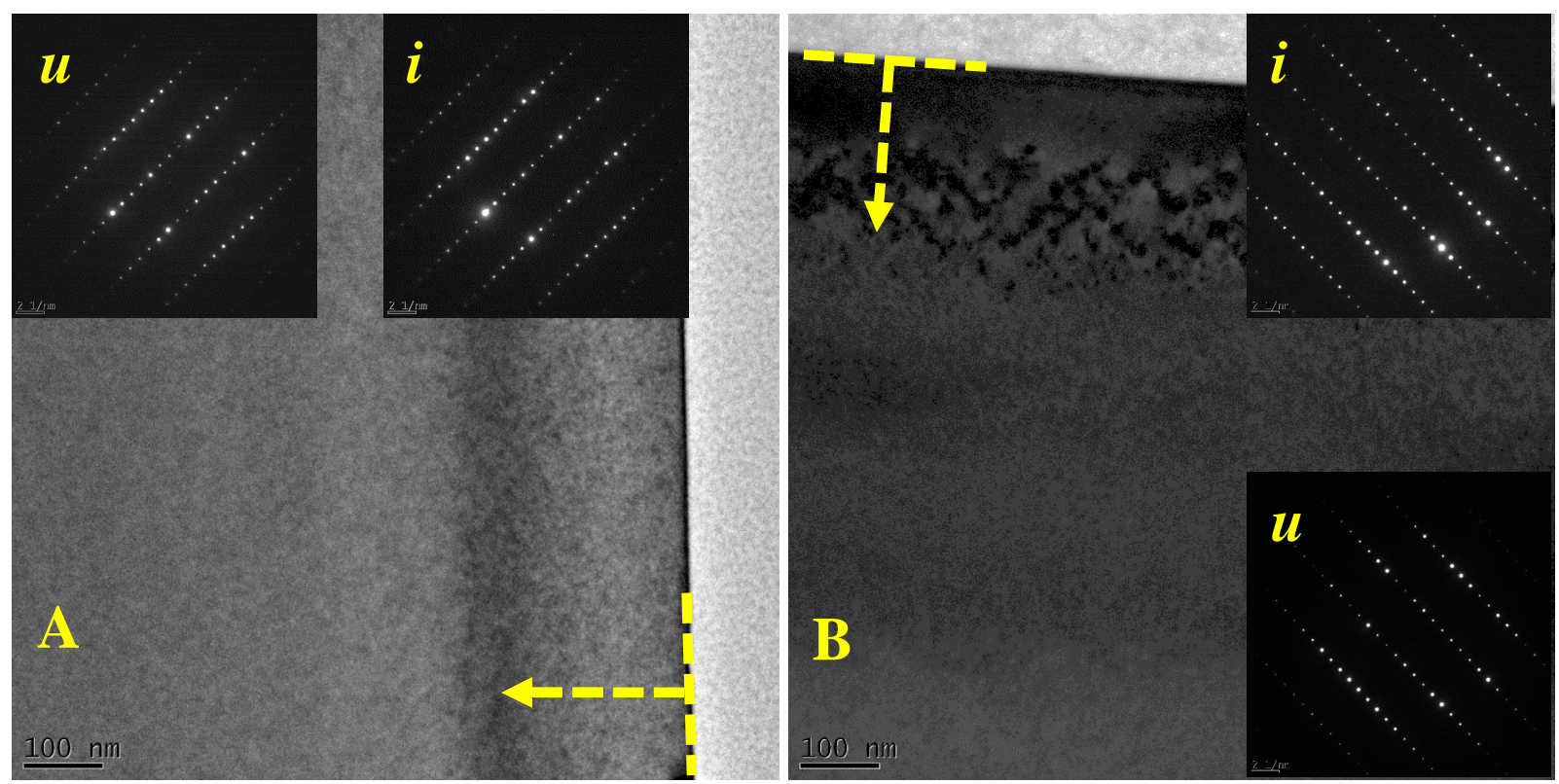

Figure 2: BF TEM micrographs of single crystal $4 \mathrm{H}-\mathrm{SiC} 5 \times 10^{14}$ ions $/ \mathrm{cm}^{2} \mathrm{AI}(\mathrm{A})$ and $1569^{\circ} \mathrm{C} 20$ hours (B) conditions, inset SAD of (11-20) zone axis, dashed line indicates implantation surface while arrow indicates direction implantation direction, $i$ ) indicates SAD from implanted region, $u$ ) indicates SAD from undamaged region.
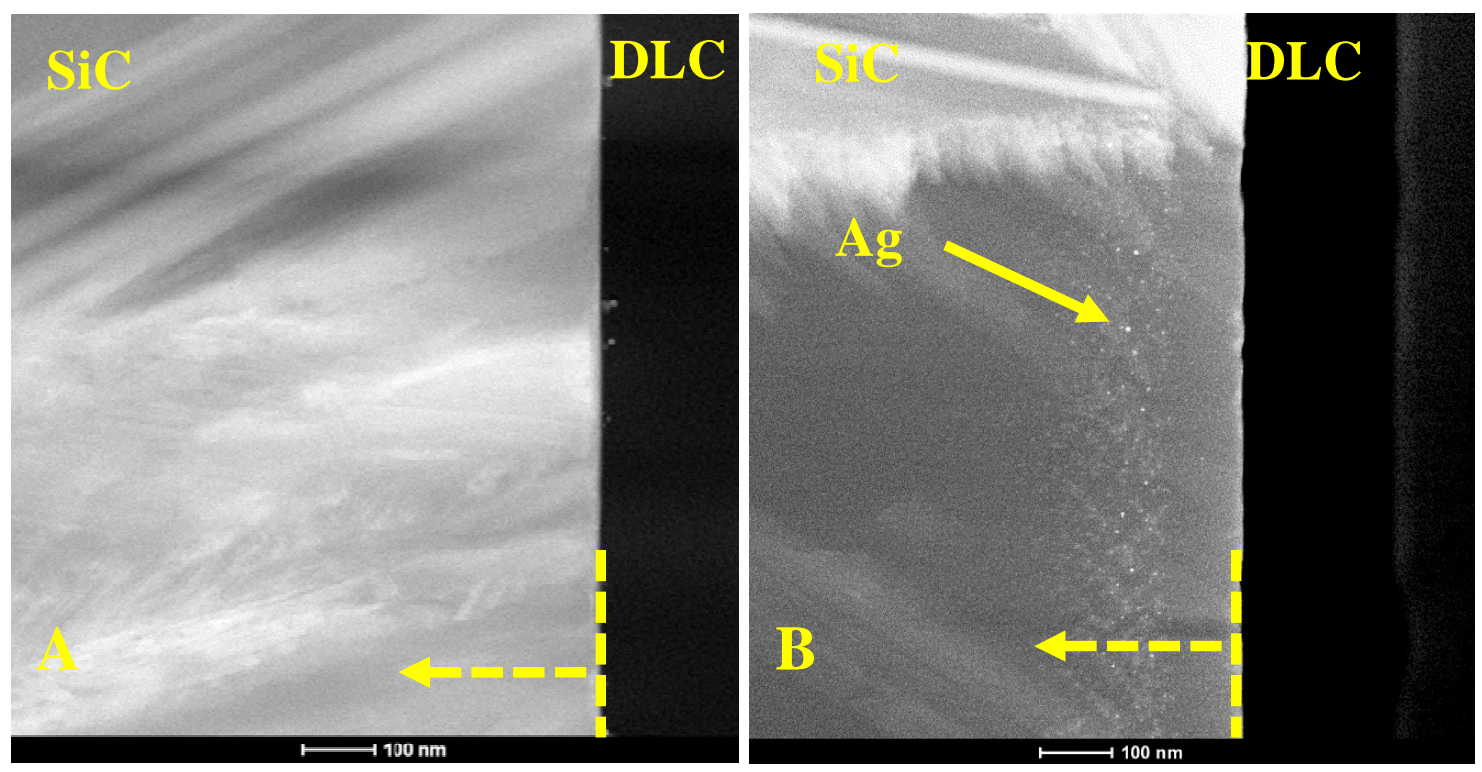

Figure 3: ADF micrographs of polycrystalline 3C-SiC $5 \times 10^{14}$ ions $/ \mathrm{cm}^{2} \mathrm{AI}(\mathrm{A})$ and $1500^{\circ} \mathrm{C} 10$ hours (B) conditions identifying fine structure after thermal exposure, dashed line indicates implantation surface while arrow indicates direction of ion implantation. 


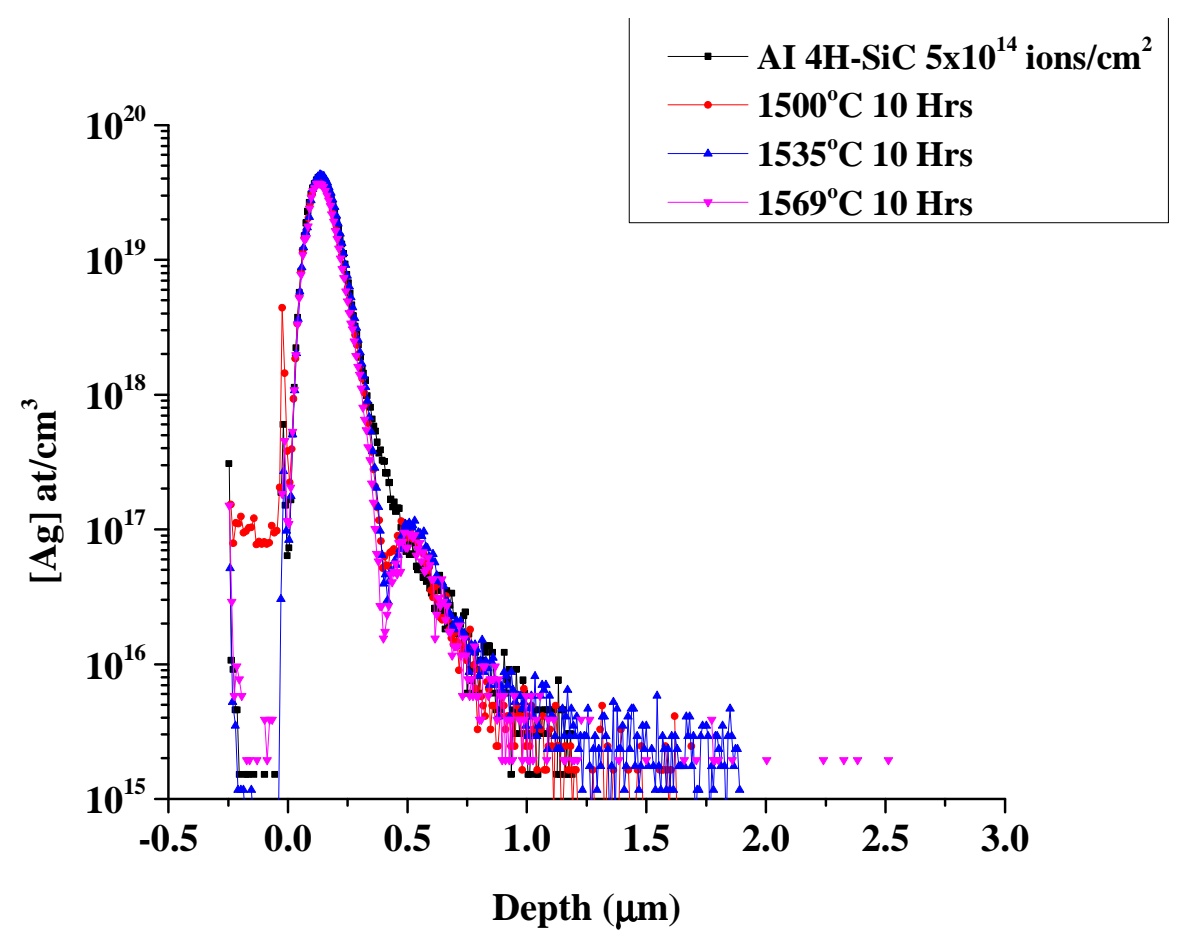

Figure 4: SIMS depth profiles of Ag in SiC for single crystal $4 \mathrm{H}-\mathrm{SiC} 5 \times 10^{14}$ ions $/ \mathrm{cm}^{2}$ AI followed by $1500-1569^{\circ} \mathrm{C} 10$ hours isochronal exposures identifying redistribution of $\mathrm{Ag}$ past the primary implantation peak.

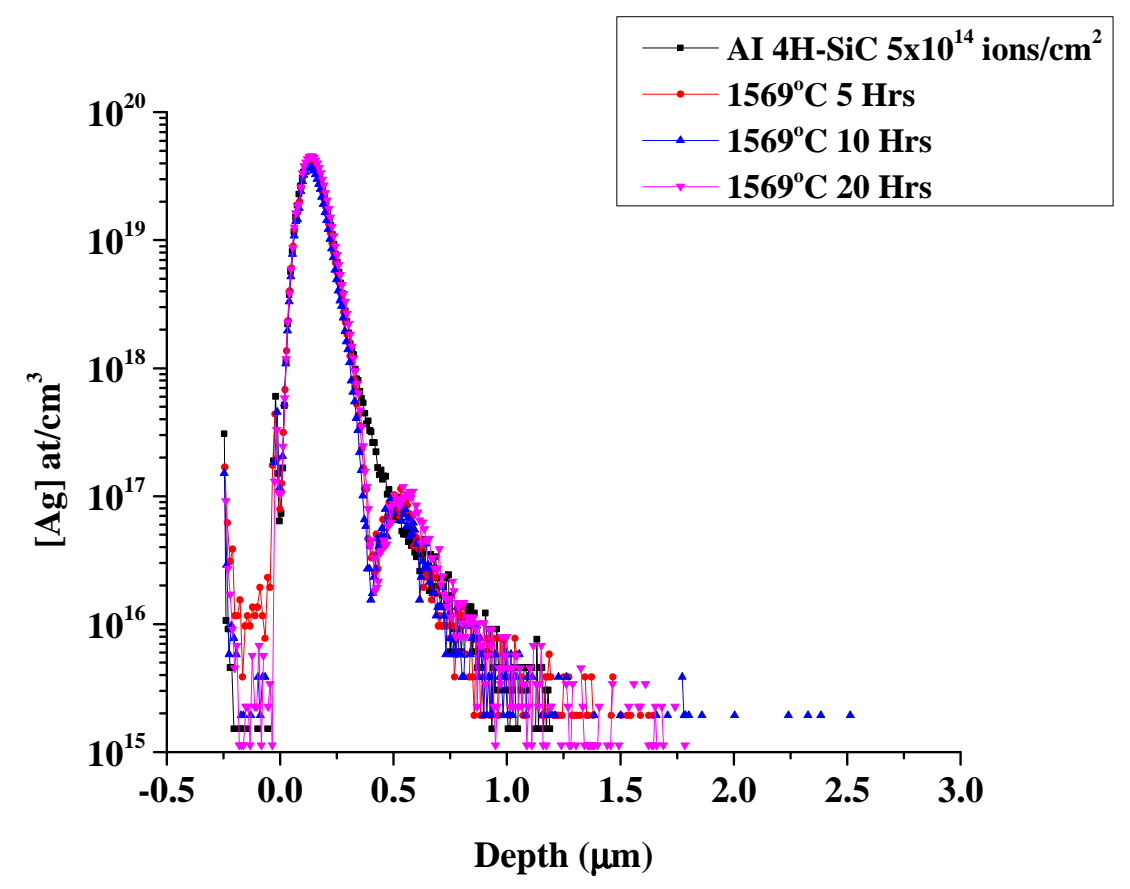

Figure 5: SIMS depth profiles of $\mathrm{Ag}$ in $\mathrm{SiC}$ for single crystal $4 \mathrm{H}-\mathrm{SiC} 5 \times 10^{14} \mathrm{ions} / \mathrm{cm}^{2} \mathrm{AI}$ followed by $1569^{\circ} \mathrm{C} \mathrm{5-20} \mathrm{hours} \mathrm{isothermal} \mathrm{exposures} \mathrm{identifying} \mathrm{redistribution} \mathrm{of} \mathrm{Ag}$ with minimal variation past the primary implantation peak. 


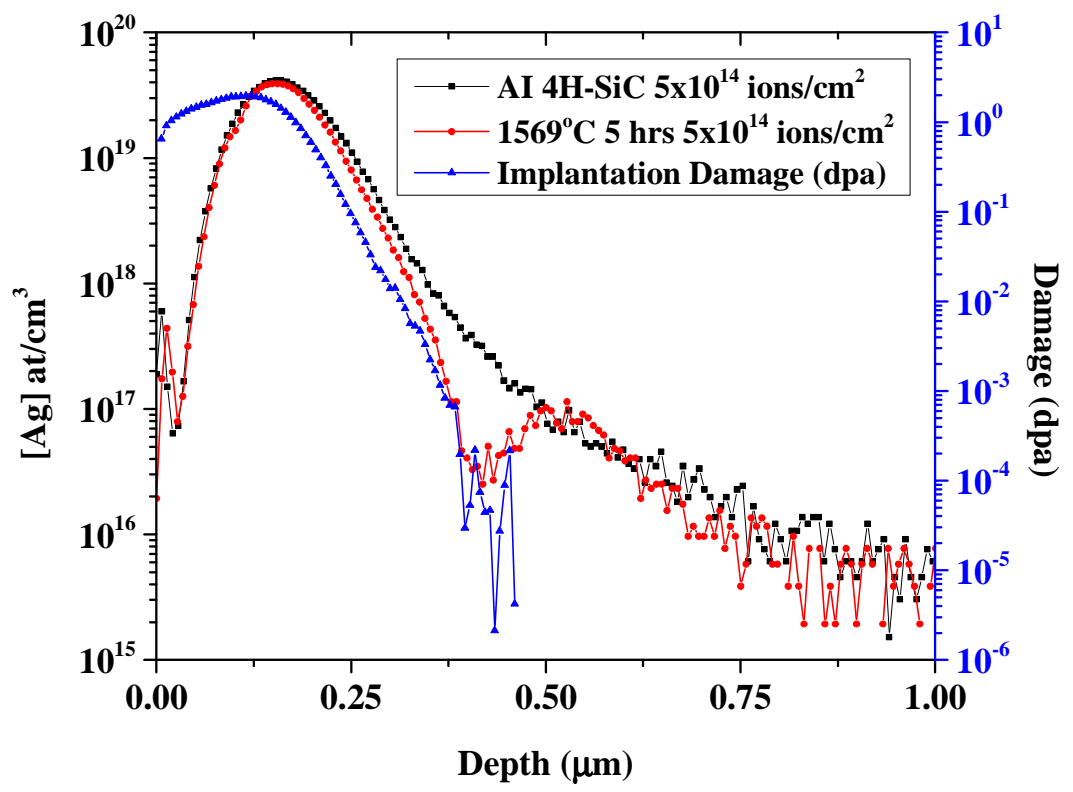

Figure 6: SIMS Ag depth profile of single crystal $4 \mathrm{H}-\mathrm{SiC} 5 \times 10^{14} \mathrm{ions} / \mathrm{cm}^{2} \mathrm{AI}$ and $1569^{\circ} \mathrm{C} 5$ hours exposure overlaid with damage profile estimated from SRIM.

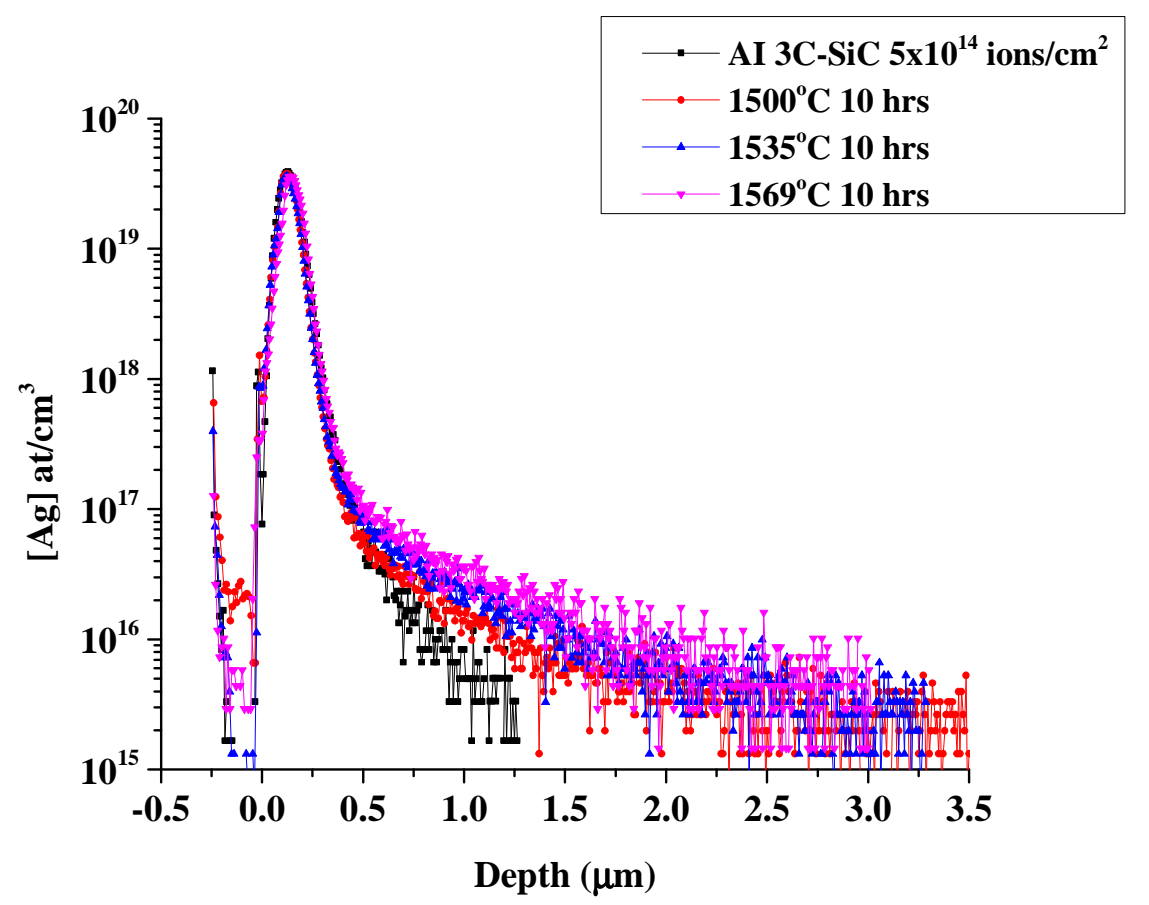

Figure 7: SIMS depth profiles of $\mathrm{Ag}$ in $\mathrm{SiC}$ for polycrystalline $3 \mathrm{C}-\mathrm{SiC} 5 \times 10^{14} \mathrm{ions} / \mathrm{cm}^{2} \mathrm{AI}$ followed by $1500-1569^{\circ} \mathrm{C} 10$ hour isochronal exposures identifying extension of $\mathrm{Ag}$ concentration past the primary implantation peak. 


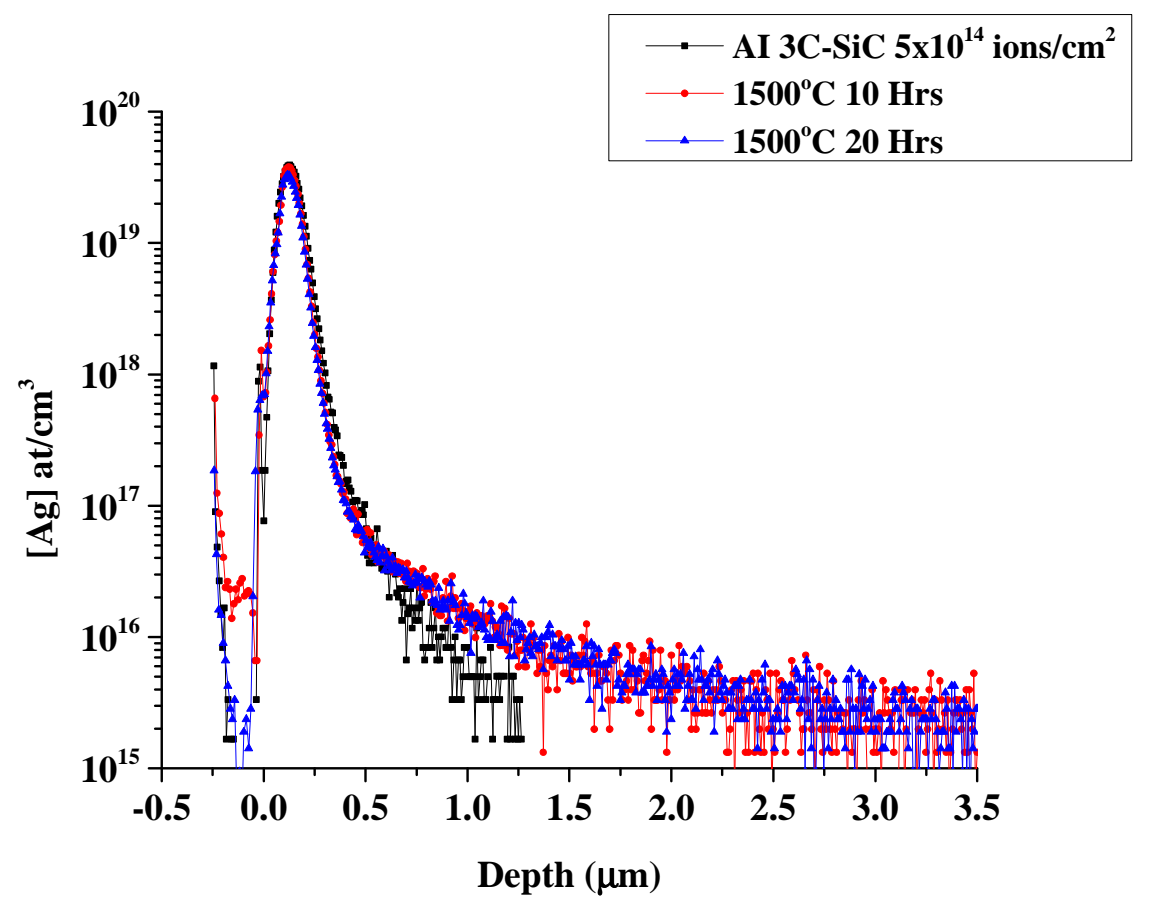

Figure 8: SIMS depth profiles of Ag in $\mathrm{SiC}$ for polycrystalline $3 \mathrm{C}-\mathrm{SiC} 5 \times 10^{14}$ ions $/ \mathrm{cm}^{2} \mathrm{AI}$, followed by $1500^{\circ} \mathrm{C} 10$ hours and 20 hours. The comparison identifies limited variation in Ag concentration between exposure conditions show no significant $\mathrm{Ag}$ concentration penetration into bulk $\mathrm{SiC}$.

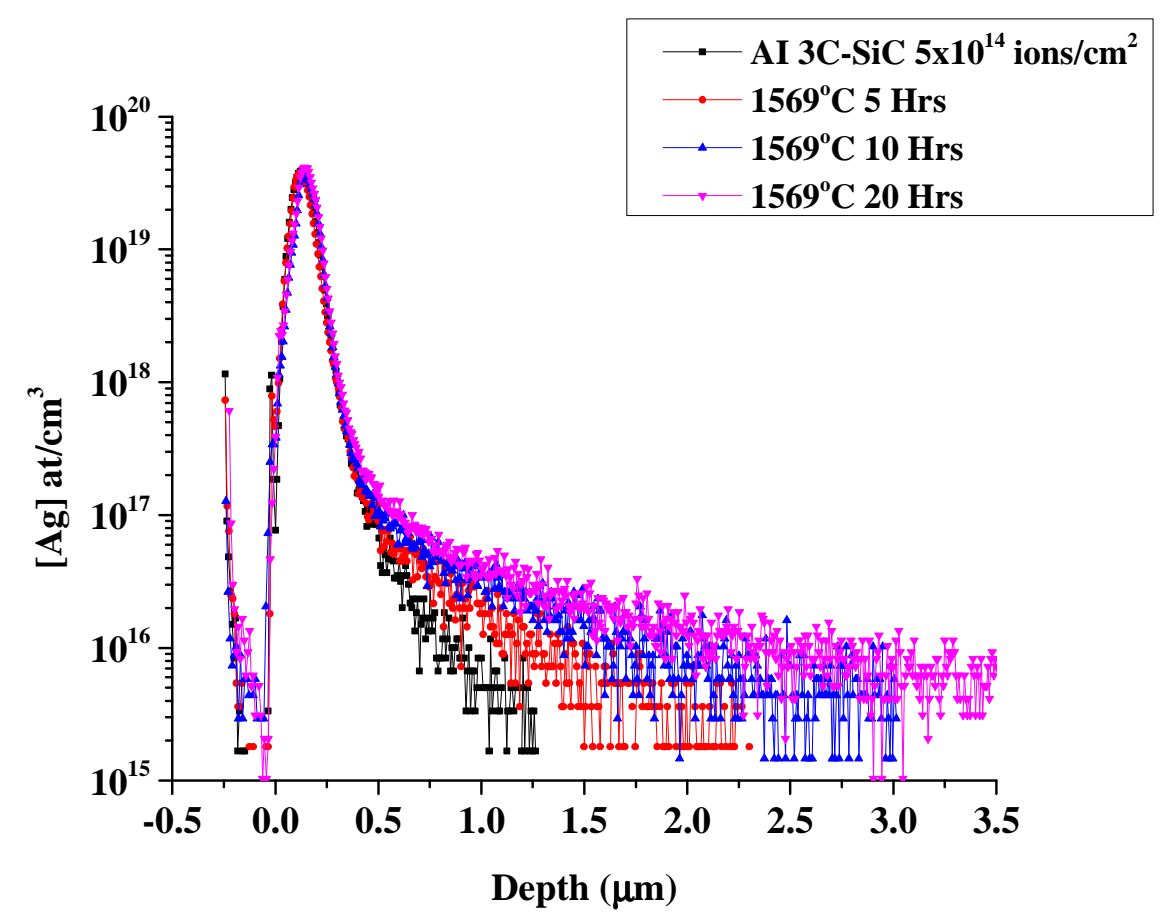

Page 32 of 34 
Figure 9: SIMS depth profiles of $\mathrm{Ag}$ in $\mathrm{SiC}$ for polycrystalline $3 \mathrm{C}-\mathrm{SiC} 5 \times 10^{14}$ ions $/ \mathrm{cm}^{2} \mathrm{AI}$ followed by $1569^{\circ} \mathrm{C} 5-20$ hours isothermal exposures. An extension of the $\mathrm{Ag}$ concentration is measured in bulk $\mathrm{SiC}$ past the primary implantation peak for all conditions with the magnitude of penetration dependent on exposure time.

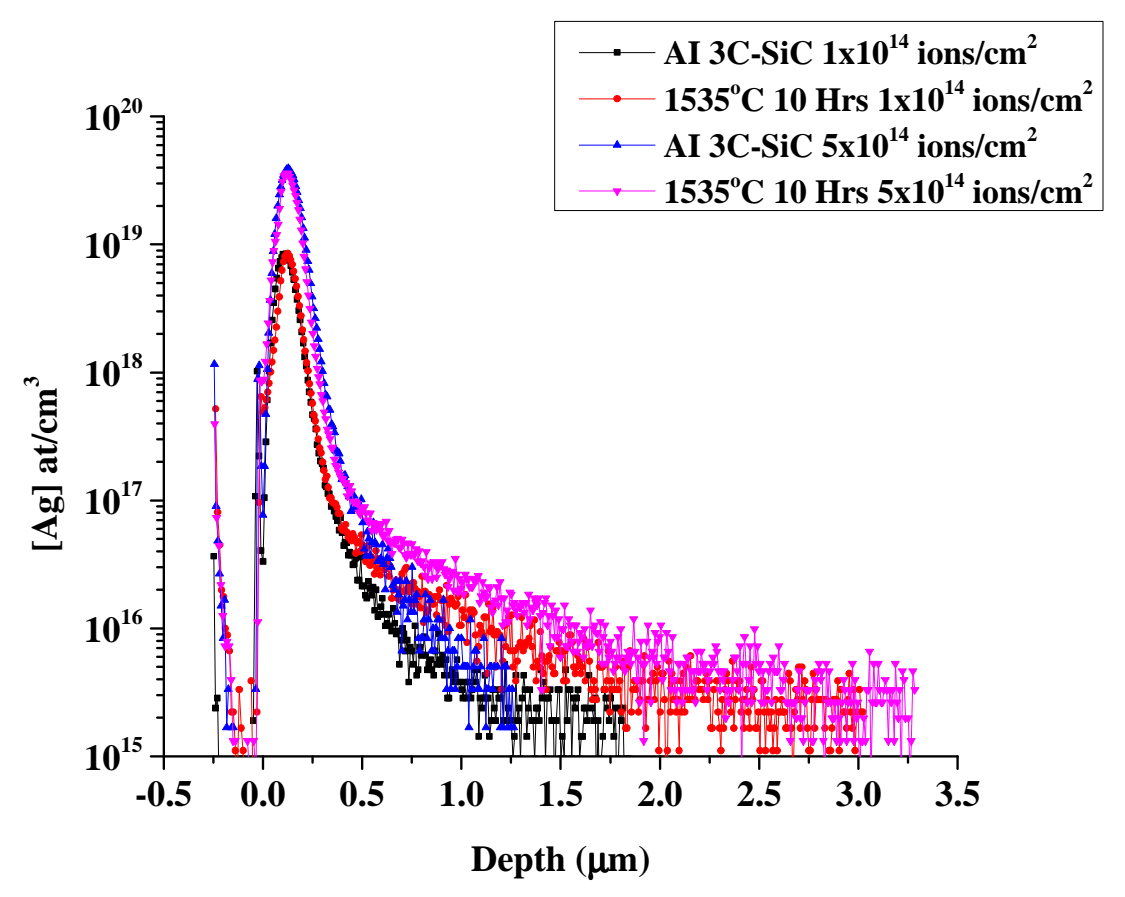

Figure 10: SIMS depth profiles for implantation dose comparison of $\mathrm{Ag}$ in $\mathrm{SiC}$ for polycrystalline 3C-SiC $1 \times 10^{14}$ ions $/ \mathrm{cm}^{2} \mathrm{AI}$ followed by $1535^{\circ} \mathrm{C} 10$ hours and polycrystalline $3 \mathrm{C}-\mathrm{SiC} 5 \times 10^{14}$ ions $/ \mathrm{cm}^{2} \mathrm{AI}$ and $1535^{\circ} \mathrm{C} 10$ hours exposures. An extension of the $\mathrm{Ag}$ concentration is measured in bulk $\mathrm{SiC}$ past the primary implantation peak for both implantation conditions. 


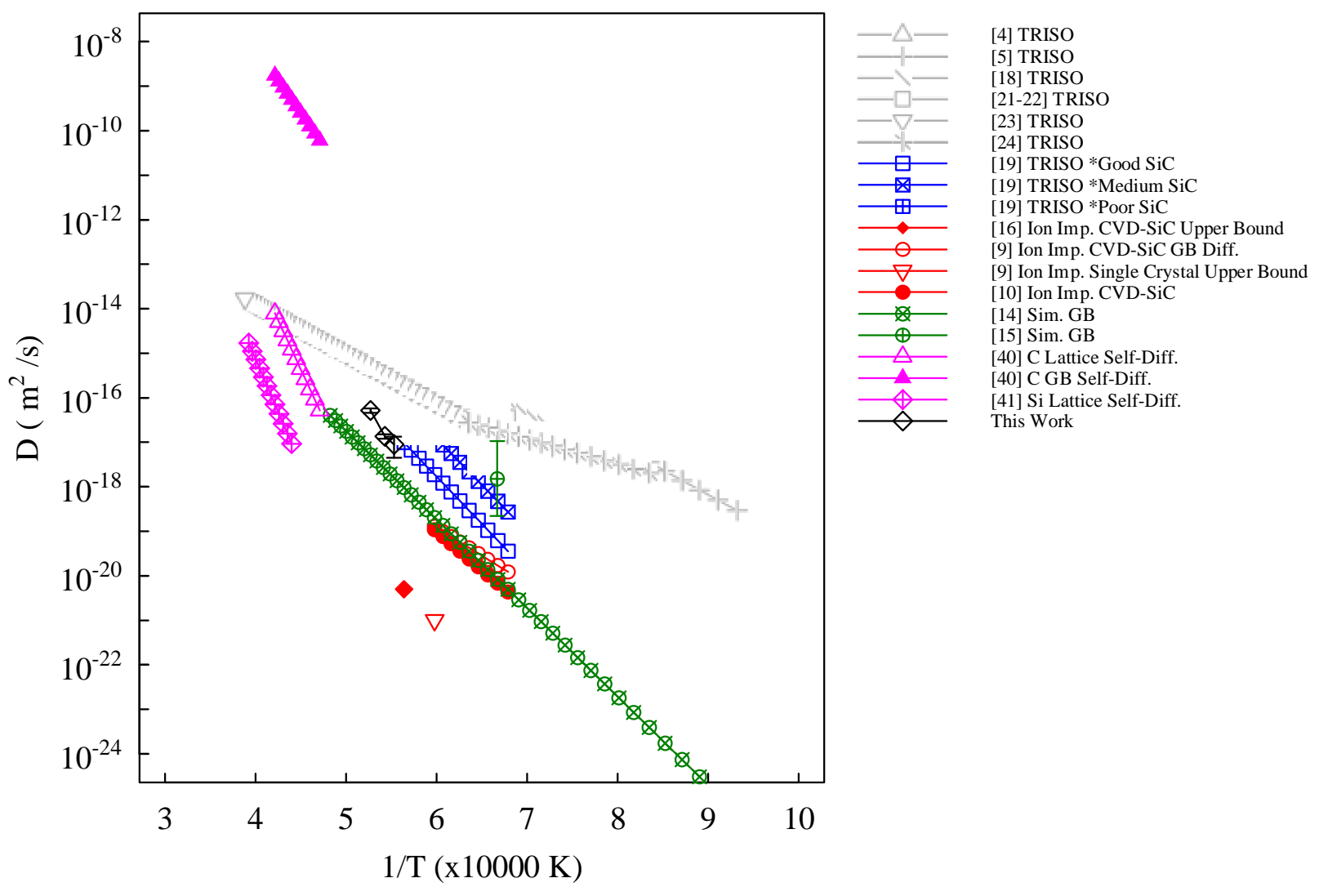

Figure 11: Comparison of diffusion coefficients, $D^{A g}$, in SiC from surrogate experiments, release from TRISO fuel, computational simulations, and this work. Si self-diffusion, $\mathrm{C}$ self-diffusion, and $\mathrm{C}$ grain boundary self-diffusion coefficients are presented for reference. The shaded régime represents $D^{A g}$ with $Q$ $=1.13-2.26 \mathrm{eV}$ and is associated with historic Ag release measurements from TRISO fuel. 